\title{
1 Long-term culture system for deep-sea mussels Gigantidas childressi
}

3 Running title: Culture of Deep-Sea Mussels

4

5 Claas Hiebenthal ${ }^{1}$, Finn-Ole Gehlert ${ }^{2}$, Mark Schmidt ${ }^{1}$, Thorsten B. H. Reusch ${ }^{1,2}$ Frank

6 Melzner ${ }^{1,2}$

7 Keywords: Gigantidas childressi, Bathymodiolus, long-term culture, methane, methanotrophs,

$8 \quad$ Rhodomonas, deep-sea

9

10 [1]: GEOMAR Helmholtz Centre for Ocean Research Kiel, Kiel, Germany

11 [2]: Christian-Albrechts-Universität, Kiel, Germany (English name is Kiel University)

12

13

14 Corresponding author: Claas Hiebenthal (chiebenthal@geomar.de) 


\section{Abstract}

26 The simulation of deep-sea conditions in laboratories is technically challenging but necessary for

27 experiments that aim at a deeper understanding of physiological mechanisms or host-symbiont

28 interactions of deep-sea organisms. In a proof-of-concept study, we designed a recirculating

29 system for long-term culture (>2 years) of deep-sea mussels Gigantidas childressi (previously

30 Bathymodiolus childressi). Mussels were automatically (and safely) supplied with a maximum

31 stable level of $\sim 60 \mu \mathrm{M}$ methane in seawater using a novel methane-air mixing system.

32 Experimental animals also received daily doses of live microalgae. Condition indices of cultured

33 G. childressi remained high over years, and low shell thickness growth could be detected, which

34 is indicative of positive energy budgets. Using stable isotope data, we demonstrate that

35 G. childressi in our culture system gained energy, both, from digestion of methane oxidizing

36 endosymbionts and from digesting particulate food (microalgae). Limitations of the system, as

37 well as opportunities for future experimental approaches involving deep-sea mussels are

38 discussed. 


\section{Introduction}

53 Most pelagic and benthic deep-sea food webs depend on limited amounts of organic material that originates in the euphotic zone and sinks to the deeper ocean (Billett et al. 1983; Gage 2003). As a result, the biomass of most deep-sea species assemblages is low (Sanders \& Hessler 1969). However, chemosynthetic deep-sea habitats such as 'hot vents' or 'cold seeps' can host a set of specialized organisms at the seafloor thriving at high abundances with biomasses of up to $30 \mathrm{~kg} \mathrm{~m}^{-2}$ (e.g. Paull et al. 1984; Sibuet \& Olu 1998). At 'cold seep' sites, high-saline and cool sea water (e.g. $120 \mathrm{~g} \mathrm{~kg}^{-1}$ and 6.5-7.2 ${ }^{\circ} \mathrm{C}$ at Brine-Pool-NR-1, Northern Gulf of Mexico) seeps from the sea floor (e.g. Smith et al. 2000; Berger \& Young 2006). The seeping water is usually highly enriched in reduced compounds, such as hydrogen sulfide or methane (e.g. Bergquist et al. 2005; Tunnicliffe et al. 2003) that serve as main energy sources for the organisms dwelling at such chemosynthetic ecosystems. Thus, these systems do not rely on solar energy for carbon fixation (Tunnicliffe et al. 2003). Thiotrophic, methylotrophic or methanotrophic microorganisms use chemical energy via oxidation and fixation of the reduced inorganic molecules from the seep water (McCollom \& Shock 1997; Duperron et al. 2007). Some of these form bacterial mats on the sea floor which grazers like shrimp or snails feed upon (Dattagupta et al. 2007). Other chemolithoautotrophic bacteria developed close symbiotic relationships with metazoans such as polychaete worms, sponges or bivalve molluscs (MacDonald et al. 1990; Tunnicliffe et al. 2003; Cordes et al. 2009; Nishijima et al. 2010). The latter allow their animal hosts (e.g. Riftia pachyptila, Bathymodiolus spp.) to indirectly obtain energy from inorganic molecules dissolved in the seawater, either by translocation of fixed carbon products to the host ('milking type') or by digestion of the bacteria by their hosts ('farming-type' carbon transfer; Streams et al. 1997).

The deep-sea mytilid mussel Gigantidas childressi (subfamily Bathymodiolinae, originally described as Bathymodiolus childressi (Childress et al. 1986; Gustafson et al. 1998)) occurs in high abundances at cold seeps from about 550 to more than $2200 \mathrm{~m}$ depth on the upper as well as the lower continental shelf in the Gulf of Mexico (Nix et al. 1995; Gustafson et al. 1998; Faure et al. 2015). The mussel holobiont utilizes methane as its only energy and carbon source (Cary et al. 1988). Metanotroph $\gamma$-proteobacteria that utilize a ribulose-monophosphate pathway (RuMP) to fix carbon ('type-1 methanotrophs') are concentrated in vacuoles of symbiont-containing bacteriocytes in the mussel outer (water facing) gill epithelium (Duperron et al. 2007; Fiala- 
Médioni et al 1986; Wentrup et al. 2014). The mussels generate a ciliary-driven water current to lead methane-rich water past their gills, where methane can diffuse into the gill tissue to supply the demands of the symbionts. The methanotroph bacteria proliferate and are eventually digested by their hosts ('farming-type' carbon transfer, Fisher \& Childress 1992; Streams et al. 1997). However, bathymodiolinid mussels do not always solely depend on carbon fixation of bacterial symbionts (Riou et al. 2010). While the host's gastrointestinal tract is often reduced in other symbiotic holobionts, this is not the case in G. childressi. Here, the mussels can still filter and digest particulate organic matter (POM) from the water column (Cary et al. 1988; Page et al. 1990). At low methane availability, bathymodiolinid mussels may even obtain the majority of the assimilated carbon from POM (Martins et al. 2008; Riou et al. 2010).

Experimental work with living deep-sea animals is extremely challenging. As it is very timeconsuming and costly to reach deep sea mussel reefs via remotely operated vehicles, in situ manipulations - such as transplantation experiments - are rare (Nix et al. 1995; Ravaux et al. 2019). On the other hand, many deep-sea animals instantly die when taken to the surface. Furthermore, it is technically challenging to recreate deep-sea pressure and water chemistry in laboratories, which makes in vitro experiments very difficult to realize as well (Huang et al. 2019). Such laboratory experiments, however, are crucial to understand for example energy metabolism at varying seawater methane concentrations, the relative importance of energy uptake via autotroph symbionts vs. filtration of POM, as well as the physiological mechanisms underlying host-symbiont energy transfer. Ultimately, experimental culturing systems that can simulate realistic seep environments could enable us to also study reproductive processes and larval development, behavior and chemotaxis - important aspects of bathymodiolinid biology that will allow us to better constrain larval drift models, population connectivity and, ultimately, guide deep-sea conservation efforts (Breusing et al. 2016).

Here, we describe a recirculating culturing system that allowed us to cultivate deep-sea mussels G. childressi for multiple years while supplying them with constant methane levels as well as POM (microalgae). We demonstrate that cultured mussels maintain and increase the ability to consume methane and are able to invest surplus energy into shell thickness growth. Tissue $\mathrm{C}$ and

111 N stable isotope data reflects a mixed diet of autotrophic symbionts and POM. We discuss

112 limitations of the culturing system as well as implications for future culture systems for deep-sea 113 organisms. 


\section{Gigantidas childressi culture}

Mussels and sampling sites

117

118

119

120

121

122

123

124

125

126

127

128

129

130

131

132

133

134

135

136

137

138

139

140

141

142

143

We cultured two batches of Gigantidas childressi specimen for altogether 39 and 31 months, respectively. The deep-sea mussels of the first batch (208 specimen, 'batch 1') were collected by E/V 'Nautilus' using ROV 'Hercules' south-west of New Orleans in the Gulf of Mexico at station GC233 ('Brine Pool NR-1'; 27 43.4076’ N, 91¹4.7798' W) in July 13th 2014 in a depth of $650 \mathrm{~m}$. At this site, cold and high-saline water seeps from the ocean floor and - due to the higher density - fills a shallow 'brine pool' which is surrounded by a G. childressi mussel bed (MacDonald et al. 1990). The mussels arrived at GEOMAR (Kiel, Germany) 14 days after being collected. The second batch of G. childressi (35 specimen, 'batch 2') was collected by MSV 'Ocean Intervention II' using ROV 'Global Explorer' north-east of the first site at station GC249 $\left(27.72879^{\circ} \mathrm{N}, 90.51690^{\circ} \mathrm{W}\right)$ in $811 \mathrm{~m}$ depth on June 18th 2017.

The mussels were transported within 4 days by ship and truck to the Fisher deep sea lab at Pennsylvania State University, State College, PA. Here, the experimental animals were cultured in a recirculating seawater aquarium system $\left(\mathrm{T}=8^{\circ} \mathrm{C}, \mathrm{S}=34\right)$ that continuously received methane-saturated seawater. Seawater methane concentrations were not quantified during this time period. Subsequently, after 2 months, animals were shipped by plane in cooled jars (T = 5 $8^{\circ} \mathrm{C}, \mathrm{S}=34$ ) to GEOMAR (travel time $<24 \mathrm{~h}$ ). There was no mortality during the transport of both batches.

\section{Description of the culture system}

The long-term deep-sea mussel culture system at GEOMAR that enabled continuous culture from July 2014 to December 2019 is located in a constant temperature room and is based on a classical recirculating aquarium system (fig. 1). The system consists of three $25 \mathrm{~L}$ glass culture tanks that receive water via gravity feed from a $25 \mathrm{~L}$ header tank at a constant flow rate of 150 $\mathrm{mL} \mathrm{min}^{-1}$. Water leaving the culture tanks via overflow pipes (PVC) is collected in a $100 \mathrm{~L}$ filter sump, where it is processed by a nitrification filter (pond external filter type 3455, EHEIM, Deizisau, Germany, filled with 12 L of HDPE bio carriers), as well as by a protein skimmer (ACF 1000V, AquaCare GmbH \& Co. KG, Gladbeck, Germany). Subsequently, the culture 
water is led by an UV lamp (hw UV-water sterilizer Model 500, Wiegandt GmbH, Krefeld, Germany) prior to being pumped back to the header tank. During the 5.5 years of culture, water temperature was kept constant at $7.9 \pm 0.2^{\circ} \mathrm{C}$ and $\mathrm{pH}$ (NBS scale) was $8 \pm 0.1$. Ammonia and nitrite concentrations were assessed bi-weekly and concentrations were always $<0.05 \mathrm{mg} \mathrm{L}^{-1}$. $30 \%$ of the system water was exchanged each week. The culture water was mixed from sandfiltered Baltic Sea water (salinity 12-20, GEOMAR central facility) from Kiel Fjord and a commercial sea salt mixture (Pro Reef, Tropic Marin AG, Hünenberg, Switzerland). Salinity was set to 34.5 .

As G. childressi is sensitive to mechanical disturbances, we placed the culture tanks on rubber mats and in two PVC-boxes with openings for water and gas lines as well as flap doors at the front to access the tanks. The boxes also allowed for culturing the mussels almost full-time in complete darkness, only interrupted by short daily check-ups of the system and occasional cleaning of aquaria. An IR-camera was installed to be able to observe the mussels (fig. 1).

\section{Methane supply}

G. childressi gain the majority of their energy from methanotroph bacteria in their gills. A sufficient supply with methane is therefore essential for a successful culture. At other institutes, bathymodiolinid mussels have been supplied with methane by repeated provision of methane enriched seawater e.g. by placing baskets with mussels for a limited time in a tank containing methane saturated seawater (Arellano \& Young 2009, 2011; suppl. tab. 1). In a similar first feeding attempt, we initially supplied $5 \mathrm{~L}$ of methane-saturated seawater (corresponding to $8 \mathrm{mmol} \mathrm{CH}_{4}$ ) into the header tank of the $200 \mathrm{~L}$ culture system twice a day. This treatment, however, was labor intensive and - as methane left the system quickly - resulted in hours of methane deficiency between methane peaks (fig. 2). Under such conditions, bathymoldiolonid mussel cultures could not be maintained for more than $\sim 6$ months (Arellano \& Young 2009, own trials). However, a Bathymodiolus azoricus recirculating culture system at LabHorta, Azores, that was continuously bubbled with methane (creating $\sim 70 \mu \mathrm{M}$ of methane; no continuous methane measurements) enabled mussel survival for more than 12 months (Colaço et al. 2006). Therefore, we also developed a system with a constant - and safe - methane supply to our G. childressi culturing system. 
175 Central to our culture system is a methane-air gas mixing device that is placed in a room next

176 door to the deep-sea mussel culture facility. This mixing device continuously enriches the

177 pressurized air ('natural' air, continuously provided by a central supply system) led to the culture

178 system with methane (fig. 3). The gas mixing device consists of a thermal gas flow sensor ('red-

179 y smart meter', 5-500 L h ${ }^{-1}$, Voegtlin Instruments, Muttenz, Switzerland) and a thermal gas flow controller ('red-y smart controller', 0.2-20 L h'-1, Voegtlin Instruments, Muttenz, Switzerland) that injects pure methane from a gas tank into the air flow, the amount depending on the flow rate and the desired methane level. A custom-made control unit (HTK Hamburg GmbH, Hamburg, Germany) processes the air flow rate signal from the flow sensor and defines the methane flow rate via the flow controller. Desired methane levels (0.0-4.0\% methane in air) can be set using a software (EasyHTK, HTK, Hamburg, Germany) on a USB-connected PC. Gas mixture flow rate can be adjusted via a flowmeter (Q-Flow V100-140, Voegtlin Instruments, Muttenz, Switzerland).

The gas mixture is then led in a gas-tight polyurethane line (PUR C 98A) from the gas mixing device room to the G. childressi culture system room. Both, the header tank and the three culture tanks of the culture system are equilibrated with the gas mixture using diffusor stones at $\sim 1.7 \mathrm{~L}$ gas mixture $\mathrm{min}^{-1}$. Also, the protein skimmer is supplied with the methane-air gas mixture instead of the methane-poor culture room air. The total gas flux of $4 \%$ methane-air mixture to the recirculation culture system is $400 \mathrm{~L} \mathrm{~h}^{-1}$. Methane concentrations in the culture system water are continuously monitored with a flow-through instrument that can determine seawater methane concentration with an accuracy of $\pm 0.1 \mu \mathrm{M}$ (CONTROS HydroC ${ }^{\circ} \mathrm{CH}_{4}$ FT, 4H-JENA

197 engineering, Kiel Germany). Culture seawater is pumped to the methane sensor at a rate of $2 \mathrm{~L}$ $198 \min ^{-1}$ (EHEIM universal pump 1200, EHEIM).

199 With the described system, we are able to maintain maximum seawater methane concentrations 200 in the aquarium system at $\sim 60 \mu \mathrm{M}$ (suppl. fig. 1, fig. 5) which corresponds well to an expected 201 methane equilibrium concentration of the injected $4 \%$ methane in air mixture of $62.14 \mu \mathrm{M}$ (using 202 Bunsen solubility coefficient at salinity 34 and $8{ }^{\circ} \mathrm{C}$; Wiesenburg and Guinasso 1979). These 203 values are higher than lower concentrations measured within Gigantidas reefs in the Gulf of 204 Mexico ('Bush Hill': 20-56 $\mu \mathrm{M} \mathrm{CH}_{4}$, 'Green Canyon': 42-10744 $\mu \mathrm{M} \mathrm{CH}_{4}$, Nix et al. 1995, 
205

206

207

208

209

210

211

212

213

214

215

216

217

218

219

220

221

222

223

224

225

226

227

228

229

230

231

232

233

234

235

Smith et al. 2000), similar to those provided by Colaço et al. (2006) to their Bathymodiolus azoricus culture $\left(\sim 70 \mu \mathrm{M} \mathrm{CH}_{4}\right)$ and allowed us to culture G. childressi for years.

\section{$\underline{\text { Safety measures }}$}

As our deep-sea mussel culturing system can be run close to the lower explosion limit for methane in air, a set of safety measures was installed to exclude the formation of an explosive atmosphere in a non-explosion safe environment:

(i) The maximum methane level that can be produced by the gas mixing device is (software-wise) restricted to $4 \%$, which is below the explosion limit of $4.4 \%$ methane in air.

(ii) The gas tank as well as the mixing device's gas leading parts (flow sensor, flow controller, flowmeter) are placed inside a fire-resistant gas tank cabinet (G90, in accordance with EN 14470-2, fire resistance of 90 minutes). Only the processor unit is placed outside, and only the gas mixture with a maximum of $4 \%$ methane leaves the cabinet in gas-safe lines (no pure methane).

(iii) Methane sensors are placed in the constant temperature room (G. childressi culture room), in the gas mixing room and in the fire-resistant gas tank cabinet containing the mixing device. A central gas alarm device raises an alarm when two alarm levels are reached: alarm level 1 at $0.88 \%$ methane (20\% of lower explosion limit, flash light) and alarm level 2 at $1.76 \%$ methane (40\% of lower explosion limit, flash light and alarm sound). At both alarm levels text messages are sent to operating personnel.

(iv) At alarm level 1 a magnetic valve between gas bottle and flow controller is closed and, hence, the methane flow is interrupted.

(v) Power failure also causes the magnetic valve to close, and the alarm device to send a text message to operating personnel.

(vi) Operating personnel controls methane consumption rates of the mixing device and methane concentration in the culture system water daily to detect potential leaks.

34 Costs for setting-up the entire deep-sea mussel culture system installed in 2013-2014 were $\sim 17,000 €$ for the culturing system (including methane sensing instrument HydroC ${ } \mathrm{CH}_{4} \mathrm{FT}$ ), 
another $\sim 17,000 €$ for the gas mixing system, and 7,000€ for the gas safety surveillance system.

Not included are repeated occurring costs for maintenance and methane consumption (at $400 \mathrm{~L} \mathrm{~h}^{-1}$ production of $4 \%$ methane-air mixture: $\sim 10,000 \mathrm{~L}$ methane, corresponding to one $50 \mathrm{~L}$ 200 bar cylinder month $^{-1}$ ).

Feeding with micro-algae

242 Apart from consumption of methanotrophic symbionts, G. childressi can obtain energy from

243 filtered organic particles as well (Cary et al. 1988; Page et al. 1990). Thus, our deep-sea mussels were also fed 5 days a week with $450 \mathrm{~mL}$ Rhodomonas sp. microalgae suspension (with $\sim 2 \times 10^{6}$ cells $\mathrm{mL}^{-1}$, corresponding to $\sim 4500$ cells $\mathrm{mL}^{-1}$ after being diluted in the $200 \mathrm{~L}$-culture system). This cryptophyte is very rich in polyunsaturated fatty acids (Renaud et al. 1999) and is permanently cultured at GEOMAR as nutritious food for filter feeding organisms in artificial seawater supplied with 'Walne's medium' including macro-nutrients, vitamins and trace elements (Walne 1970).

\section{Experimental observations and growth of cultured deep-sea mussels}

252 Two sets of experiments were conducted during the culture system development process. In the 253 first set, $G$. childressi from batch 1 were cultured with 20-30 $\mu \mathrm{M}$ methane in seawater to obtain 254 first insights into the mussels' energy uptake. Based on these findings we decided to increase the seawater methane concentration and to start culturing mussels from batch 2 under three different

256 nutritional regimes during the second set of experiments: i) exclusively methane $(60-70 \mu \mathrm{M})=$

257 'm', ii) methane (60-70 $\mu \mathrm{M})$ and microalgae (Rhodomonas sp.) = 'a+m', and exclusively 258 microalgae (Rhodomonas sp.) = 'a'. To achieve the third nutrition treatment (without methane) 259 one of the aquaria was separated from the main culturing system and the mussels were fed with Rhodomonas sp., only $\left(250 \mathrm{~mL} \mathrm{~d}^{-1}\right)$. The water of this aquarium was treated with a nitrification filter (ecco pro 200, EHEIM) and a protein skimmer (Power Skimmer WT350, Sander, Uetze-

262 Eltze, Germany) placed in an extra 25 L-filter sump. The G. childressi in one of the aquaria of 263 the main system continued to receive Rhodomonas sp. (250 $\mathrm{mL} \mathrm{d}^{-1}$ poured directly into the 264 aquarium) and methane - while phytoplankton addition was stopped in the other ('m')-aquarium.

265 The 3-step filtering of seawater in the main recirculation system (by nitrification filter, protein 
skimmer and UV-clearer) prevented not-consumed microalgae from being transported to the 'm'-treatment aquarium. Aquaria with mussels that were fed with microalgae received $125 \mathrm{~mL}$ Rhodomonas sp. suspension twice a day. The second set of experiments aimed at a deeper understanding of G. childressi energy acquisition modes (tab. 2).

\section{$\underline{\text { Methods }}$}

Condition of cultured deep-sea mussels: To measure the general condition of cultured $G$. childressi, the condition index $\left(\mathrm{C}_{\mathrm{i}}\right)$ was used as the quotient of ash-free dry weight and inner mussel shell volume (Smith 1985; Davenport \& Chen 1987; Smith et al. 2000, eq. 1).

To assess the $\mathrm{C}_{\mathrm{i}}$, the mussels' soft tissue was removed from the shells, dried for 24 hours at 80 ${ }^{\circ} \mathrm{C}$ and the dry weight was measured. Subsequently, the tissue was incinerated at $500{ }^{\circ} \mathrm{C}$ to measure the ash weight which was subtracted from the dry weight to obtain ash-free dry weight (AFDW).

The inner shell volume was measured indirectly via the weight of fine silica sand (grading 50$1000 \mu \mathrm{m})$ that filled the shell: The mussel shells were filled with water to ensure a balanced position and glued to glass slides. After drying, the shells were weighed with and without sand. A calibration curve produced using 1 to 40 units of a standardized cup of exact $0.2602 \mathrm{~mL}$ (suppl. fig. 2) allowed us to estimate shell volume from the sand's weight (eq. 2):

$$
\text { (2) shell volume }(m L)=\text { sand mass }(g) \times 0.7728\left(\frac{\mathrm{mL}}{\mathrm{g}}\right)
$$

$$
\mathrm{R}^{2}=0.99, \mathrm{n}=32, \text { sand volume range } 0.26-10.41 \mathrm{~mL}
$$

Shell lengths of the sacrificed G. childressi were also measured to correlate the mussels' condition with their size. $\mathrm{C}_{\mathrm{i}} \mathrm{s}$ of sub-samples of cultured deep-sea mussels were assessed three 
292

293

294

295

296

297

298

299

300

301

302

303

304

305

306

307

308

309

310

311

312

313

314

315

316

317

318

319

320

321

times: once with mussels of batch 1 (12 specimens in August 2016), twice with mussel of batch 2 (3 specimen in August 2017, 12 specimens in November 2019).

Growth of cultured deep-sea mussels: Shortly after the start of the G. childressi culture efforts with mussel batch 1 on September 11th 2014, the animals were stained with the fluorescent dye calcein (Sigma C0875). Calcein can be excited at $488 \mathrm{~nm}$ and emits at $515 \mathrm{~nm}$ and is rapidly incorporated into the shell of molluscs (Holcomb et al. 2013, Ramesh et al. 2017). Hence, shell length and thickness growth rates can be followed using a fluorescence stereo microscope (Nedoncelle et al. 2013). Calcein was added to the culture system (50 $\left.\mathrm{mg} \mathrm{L}^{-1}\right)$ and subsequently over the course of 2 months - diluted via regular water changes, allowing the mussels to incorporate the dye into newly grown shell material. In August 2016, twelve G. childressi individuals were sacrificed to analyze growth of calcein stained animals. Shells were analyzed using a Leica M165 FC stereo microscope at magnifications between 40-120 fold using a GFP filter set (excitation: BP 450-490 nm, emission: LP $515 \mathrm{~nm}$ ) and EL6000 light source (Leica Camera AG, Wetzlar, Germany). Shells were first analyzed for longitudinal growth, then manually broken along the length axis and imaged in cross section at the leading edge (see fig. 4). Images were analyzed using Leica LAS X software. To follow G. childressi growth rates macroscopically as well, all mussel shells were furthermore marked with small scrapings at the outer shell margin (using a rotary tool to remove the periostracum at these locations without perforating the shell).

\section{Methane and oxygen consumption of deep-sea mussels: To measure G. childressi gas} consumption rates the animals were placed into gas tight closed respirometer vessels $(500 \mathrm{~mL}$ glass bottles) that were prepared with oxygen sensor spots (SP-PSt3-NAU, PreSens Regensburg, Germany; resolution $\pm 0.1 \%$ at $20.9 \% \mathrm{O}_{2}$ or $\pm 0.04 \mathrm{mg} \mathrm{L}^{-1}$ at $9.1 \mathrm{mg} \mathrm{L}^{-1}$ ) to measure oxygen concentrations with a four-channel Oxy-4 micro instrument (PreSens) via optical fibers (e.g. Vajedsamiei et al. 2021). Temporal resolution of oxygen measurements was $4 \mathrm{~h}^{-1}$ (suppl. fig. 7). The time animals needed to recover following transfer into respirometers (i.e. the time until they started to open their valves to filter water) varied between 1 and 3 hours and could be estimated from the point of time when respirometer oxygen concentrations started to decline. 
322 Periods of 2 or more consecutive measurements without decreasing oxygen content indicated

323 shell closure and cessation of filtration and gas exchange rates (suppl. fig. 7; e.g. Vajedsamiei et

324 al. 2021). Measurements were stopped after 8 hours.

325 Methane consumption rates were measured as two-point measurements in parallel to the

326 respiration measurements using water samples from the respirometers. For this purpose, water

327 samples were taken (in gas-tight $20 \mathrm{~mL}$ brown glass bottles) at the beginning and at the end of

328 the measuring period. Gas (air) bubble-free water samples were poisoned immediately after

329 sampling with $100 \mu \mathrm{L}$ saturated mercury-chloride solution. During the measurement period the

330 measuring chambers remained closed and without any gas (air) bubbles. Methane concentrations

331 were measured later on a HP 5890 gas-phase chromatograph (Hewlett-Packard, Santa Clara,

332 USA) using the headspace technique (Bange et al. 2010). During the measurements of batch 1

333 mussels and the first measurements of batch 2 mussels, activity of mussels could be estimated

334 from parallel respiration measurements, see above (suppl. fig. 7). During the $2^{\text {nd }}$ measurements

335 of methane consumption of batch 2 mussels, however, the mussels' activity (open vs. closed

336 valves) was individually monitored using cameras (QuickCam®, Logitech, Lausanne,

337 Switzerland, connected via USB to a PC). Thus, we were able to normalize methane

338 consumption to the amount of time animals were active (open valves, high respiration rates).

339 A water filled respirometer during each run was used as the control for bacterial oxygen and

340 methane consumption during measurements and bacterial control respiration rates were always

$341<1 \%$ of experimental animal respiration rates. Methane and oxygen consumption rates $\left(\mathrm{MCH}_{4}\right.$

342 and $\mathrm{MO}_{2}$, respectively) per g soft body mass were calculated as the difference of gas

343 concentrations at the start $\left(\mathrm{C}_{\text {start }}\right)$ and at the end of the measurement $\left(\mathrm{C}_{\text {end }}\right)$, multiplied by the

344 volume of the measuring chamber and followed by subtraction of control (microbial) respiration

345 rates (eq. 3):

(3) gas consumption $\left(\frac{\mu m o l}{g * h}\right)=$ 
The soft tissues mass of the utilized mussels could not be assessed directly as $20-50 \%$ of the soft tissue (the gills) were sampled for symbiont density analyses. Total soft tissue could not be weighed before gill sampling as this would have corrupted the samples. Hence, soft tissue masses were indirectly estimated from a total weight - wet weight relation obtained from mussels sacrificed for $\mathrm{C}_{\mathrm{i}}$ analyses (eq. 4, suppl. fig. 3):

(4) Wet weight $(\mathrm{g})=$ total weight $(g) \times 0.2369, \mathrm{R}^{2}=0.976, \mathrm{n}=9$, shell length range: $24-73$ $\mathrm{mm}$

Methane and oxygen consumption measurements were conducted with both batches of animals at different time periods: animals of batch 1 following culture at 20-30 $\mu \mathrm{M}$ methane $(\mathrm{n}=12)$ and animals of batch 2 following culture under the three different nutrition regimes: ' $m$ ' , ' $a+m$ ' and 'a' ( $n=3$ each). Another set of measurements of the same batch 2 mussels' methane consumption was conducted after another 19.5 months of the respective treatments to explore possible acclimation effects of $G$ childressi or symbionts over time (tab. 1).

\section{G. childressi filtering behavior in relation to water methane concentration: Repeated IR-camera} observations of cultured $G$. childressi suggested that the deep-sea mussels react to changes in culture seawater methane concentrations with increased or reduced filtering activity. To test whether these observations can be repeated under controlled conditions, a simple experiment was performed in one of the aquaria: nine batch 2 G. childressi individuals from the three treatments were placed into a perforated acrylic rack with multiple chambers to constrain animals (suppl fig. 4). Strong aeration and an additional circulation pump (Koralia, 900, HYDOR srl, Bassano del Grappa, Italy) increased water movement in the aquarium and into the acrylic rack. Mussel filtering behavior was observed with the IR-camera while culture system seawater methane concentrations were raised or lowered. During the experimental observations, methane concentration was raised in a stepwise manner from 0 to $\sim 60 \mu \mathrm{M}$ in daily increments, and then, subsequently, reduced stepwise back to $0 \mu \mathrm{M}$ (suppl. fig. 5). This procedure was repeated three times. The IR-camera took pictures at a rate of $30 \mathrm{~h}^{-1}$. The pictures were analyzed after the 
experiment was finished by creating time lapse videos. Videos were observed and periods with opened valves were quantified for each animal. Mussels were assumed to be actively filtering with opened valves. G. childressi filtering activity was expressed as minutes of activity per hour.

Particulate food consumption of deep-sea mussels. In order to estimate the fraction of energy that can be obtained through consumption of particulate organic matter, we conducted two experiments (tab. 1) similar to those published by Page et al. (1990) using microalgae as food source.

In the first experiment, six batch 1 G. childressi were individually placed into $500 \mathrm{~mL}$ experimental units (EUs). EUs were glass bottles filled with seawater and continuously aerated with methane-air mixture (3\% methane; corresponding to $40-50 \mu \mathrm{M})$ via diffusor stone placed in the center of each EU to aid internal mixing. Two further EUs were used as controls and did not contain animals. Before microalgae were added to the EUs, $1 \mathrm{~mL}$ samples were taken to determine background particle concentrations. Microalgae culture concentrations were measured using a flow cytometer (Accuri 6, BD Biosciences, San Jose, CA). Cell concentrations at the start of the experiments were set to 7000 cells $\mathrm{mL}^{-1}$ (Foster-Smith 1975; Page et al. 1990). Microalgae were allowed to be evenly distributed by the circular currents in the EUs. Hence, first samples $\left(\mathrm{t}_{0}\right)$ were taken after 15 minutes when mixing was complete. Further samples were taken after 3, 7, 11 and 24 hours. At each sampling time point, $1 \mathrm{~mL}$ of seawater was taken from each EU and microalgae cell concentrations were measured on the flow cytometer. The experiment was conducted first with Rhodomonas sp. (cell size: 5-8 $\mu \mathrm{m}$ ) and subsequently with Nannochloropsis sp. (cell size: 2-4 $\mu \mathrm{m}$ ) to test for possible feeding preferences of G. childressi. Clearance rates $\left(R_{C}\right)$ were calculated after Coughlan (1969; Jacobs et al. 2015):

$$
\text { (5) } R_{C}\left(\frac{m L}{h}\right)=\frac{V}{t} \times\left\{\left(\ln \frac{C 0}{C t}\right)-\left(\ln \frac{C \prime 0}{C \prime t}\right)\right\}
$$

Where ' $\mathrm{V}$ ' is the water volume $(\mathrm{mL})$, ' $\mathrm{t}$ ' is the time since start of the experiment $(\mathrm{h})$, ' $\mathrm{C}_{0}$ ' and ' $\mathrm{C}_{\mathrm{t}}$ ' are the cell concentrations of EUs with mussels filtering at $\mathrm{t}_{0}$ and $\mathrm{t}$, and ' $\mathrm{C}$ ' 0 ' and ' $\mathrm{C}{ }_{\mathrm{t}}$ ' of controls at $\mathrm{t}_{0}$ and $\mathrm{t}$, respectively (cells $\mathrm{mL}^{-1}$ ). 
In the second experiment, we used each three batch $2 G$. childressi specimen from the three different nutritional treatments. The mussels were placed in $500 \mathrm{~mL}$ EUs that were equilibrated with $4 \%$ methane-air mixture (corresponding to 60-70 $\mu \mathrm{M}$ ) as described above. Three additional EUs were used as controls. Cell concentrations were measured with a Coulter Counter (Z2 Coulter particle count and size analyzer, Beckman Coulter TM, Brea, CA) which allowed for quicker data acquisition. Microalgae density was set to $\sim 7000$ cells $\mathrm{mL}^{-1}$ at the start of the experiments. Samples were taken after 15 minutes $\left(\mathrm{t}_{0}\right)$ and after 3, 7 and 11 hours. Microalgae consumption rate of $G$. childressi from the 'a' treatment group were conducted twice: Once in water equilibrated with $4 \%$ methane-air mixture and once in water without methane.

Stable isotope $\left(\delta^{15} N, \delta^{13} C\right)$ analyses of G. childressi cultured under different nutrition regimes. We used batch 2 deep-sea mussel specimens acclimated to all three nutritional regimes (tab. 1) for stable isotope $\left(\delta^{15} \mathrm{~N}, \delta^{13} \mathrm{C}\right)$ analyses. In addition, three specimens of batch 2 were sampled directly when they arrived in our lab.

The soft tissues of the mussels were frozen at $-20{ }^{\circ} \mathrm{C}$, subsequently freeze-dried until all water had left the sample and ground to powder. Total particulate carbon and nitrogen content and isotopic compositions were analyzed according to Sharp et al. (1974). $0.5 \mathrm{mg}$ of each sample was weighted into tin cups. Inorganic carbon was removed by addition of $0.2 \mu \mathrm{l}$ of $10 \% \mathrm{HCl}$. After drying the samples, the procedure was repeated once more and the cups were closed and analyzed. The samples were then combusted in a CN-analyzer (Flash IRMS EA IsoLink CN Thermo Fisher) connected to a DELTA V Adv MS isotope ratio mass spectrometer (Thermo Fisher Scientific, Waltham, MA). Isotopic rations $\delta^{15} \mathrm{~N}$ and $\delta^{13} \mathrm{C}$ were calculated as:

$$
\text { (6) } \delta \mathrm{X}(\% \mathrm{o})=\left\{\left(\frac{R_{-} \text {sample }}{R_{-} \text {standard }}\right)-1\right\} \times 1000
$$

Where ' $\mathrm{X}$ ' is ${ }^{15} \mathrm{~N}$ or ${ }^{13} \mathrm{C}$ and ' $\mathrm{R}$ ' is ${ }^{15} \mathrm{~N} /{ }^{14} \mathrm{~N}$ or ${ }^{13} \mathrm{C} /{ }^{12} \mathrm{C}$, respectively. As primary standards, pure $\mathrm{N}_{2}$ and $\mathrm{CO}_{2}$ gases were used, calibrated against IAEA reference standards N1, N2, N3, NBS22, and USGS24. In addition to the standard calibration at the beginning of each run, standard materials (caffeine, peptone, and acetanilide) were also included within runs to identify any drift 
437 and ensure accuracy and full combustion of the samples during analysis. Overall analytical

438 precision was $\pm 0.1 \%$ for $\delta^{15} \mathrm{~N}$ and $\delta^{13} \mathrm{C}$.

439 Rhodomonas sp. culture samples were gently centrifuged for 15 minutes at $800 \mathrm{rpm}$. and the

440 supernatant was discarded. The concentrated cell suspension was frozen at $-20{ }^{\circ} \mathrm{C}$, subsequently

441 freeze-dried and ground to powder as described above.

442 To determine stable carbon isotope fractionation between methane and cultured deep-sea

443 mussels, two samples of the $4 \%$ methane-air mixture were taken with Tedlar ${ }^{\circledR}$ gas sampling

444 bags. Methane was separated from other gases by gas chromatography and subsequently

445 converted to $\mathrm{CO}_{2}$ in a combustion oven, which is connected to a Thermo MAT 253 continuous-

446 flow isotope ratio mass spectrometer (CF-IRMS, Thermo Fisher Scientific, Waltham, MA). The

447 measured ${ }^{13} \mathrm{C} /{ }^{12} \mathrm{C}$-ratios are given in the common delta notation versus Vienna PeeDee

448 Belemnite (VPDB). Reproducibility of $\pm 0.3 \%$ (2 SD) is based on repeated measurements of

449 laboratory reference gas.

450 Finally, shifts of soft tissue stable isotope composition after transplantation to a site with

451 differently fractionated $\mathrm{N}$ or $\mathrm{C}$ can be interpreted as turnover as a measure of metabolic rates

452 (Dattagupta et al. 2004). In that sense, annual carbon turnover rates of whole G. childressi soft

453 tissue were calculated as:

454

455

(7) $\% \Delta \delta^{13} \mathrm{C}_{\mathrm{ann}}=\left(\delta^{13} \mathrm{C}_{\mathrm{mc}}-\delta^{13} \mathrm{C}_{\mathrm{t} 0}\right) /\left(\delta^{13} \mathrm{C}_{\text {source }}-\delta^{13} \mathrm{C}_{\mathrm{t} 0}\right) \times 100 / \mathrm{t}_{\mathrm{c}} \times 12$

457 where ' $\mathrm{m}_{\mathrm{c}}$ ' are cultured mussels, $\mathrm{t}_{0}$ are the mussels sampled right after arrival at GEOMAR and 458 ' $\mathrm{t}_{\mathrm{c}}$ ' represents the time (duration) of the culture [months].

$460 \quad \underline{\text { Results }}$

Performance of the methane supply system

462 The continuous air-methane mixture supply to our recirculating aquarium system with up to $4 \%$

463 methane allowed for extended near-equilibration $\mathrm{CH}_{4}$ concentrations above $60 \mu \mathrm{M}$ and, hence, a

464 long-term culture of G. childressi (figs. 2 and 4, suppl. fig. 1). Deviations from optimal (stable) 
$\mathrm{CH}_{4}$ concentrations were caused intentionally due to major improvements of the gas mixture supply (improvements of gas flow volume in system in February 2015 and July 2017) and maximal \% $\mathrm{CH}_{4}$ level (July 2017) could be realized, or when experiments were conducted that had to take place in the same culture system (suppl. fig. 1). During such experiments, desired $\mathrm{CH}_{4}$ levels could be selected by changing the $\% \mathrm{CH}_{4}$ in the air-methane mixture bubbled into the system between $0 \%$ and $4 \% \mathrm{CH}_{4}$ (fig. 5). More seldom (6 time over the entire culture period) technical malfunctions caused further reductions of methane concentrations. Overall, these intentional and non-intentional incidents together accounted for a significant amount of variation in the seawater methane concentration, most prominently so during the phase October 2017 March 2019, where the methane concentration was 57.3 $\mu \mathrm{M} \pm 19.7 \mathrm{SD}$ (suppl. fig. 1). However, when excluding the phases of experimental work during that phase, the methane concentration was $65.7 \mu \mathrm{M} \pm 5.4 \mathrm{SD}$ demonstrating that the system is capable to maintain very stable seawater methane concentrations.

\section{Condition and Growth.}

Batch 2 G. childressi acclimated to $\mathrm{CH}_{4}$ ('m') or $\mathrm{CH}_{4}$ and microalgae addition ('a+m'), maintained condition indices similar to those of the freshly imported animals (' $\mathrm{t}_{0}$ ') even after more than two years of culture (fig. 6a). Only smaller $G$. childressi specimen of batch 1 that were cultured at less optimal $\mathrm{CH}_{4}$ concentrations and batch 2 mussels that were exclusively fed with microalgae ('a', no $\mathrm{CH}_{4}$ ) were characterized by lower condition indices. In the latter treatment, only half as many $G$. childressi survived when compared to treatments with $\mathrm{CH}_{4}$ supply (fig. 6b). Data from animals freshly ( $<1$ day post capture) collected at the same site as our batch 1 mussels (GC 233: 'Brine Pool NR-1) indicate ca. 2-fold higher condition factors than can be reached in the field (Smith et al. 2000).

Good condition indices in batch 2 animals that received methane as energy source (' $\mathrm{m}$ ' and ' $a+m$ ') suggest that energy supply was sufficient to prevent consumption of body mass during the culturing experiment. The observation of a net shell thickness increase in all examined specimen furthermore indicates that surplus energy could be invested into anabolic processes (fig. 7). Shell thickness increased exponentially with mussel size (fig. 7b). On the other hand, 
shell length increase remained low: calcein markings of 10 individual batch 1 shells revealed an increment of shell lengths between 0 to $1700 \mu \mathrm{m}$ during the culturing period of 21 months (fig. 7a), independently of mussel size. No shell length increments were observed in two animals. Only one mussel grew $1.7 \mathrm{~mm}$ in shell length, all other animals grew by $400 \mu \mathrm{m}$ or less. No shell length growth could be detected in batch 2 animals, which were marked via shell (periostracum) scrapings.

\section{Methane and oxygen consumption.}

Batch 1 mussels' methane consumption rates ranged between $0.03 \mu \mathrm{mol} \mathrm{g}^{-1} \mathrm{~h}^{-1}$ and $0.17 \mu \mathrm{mol} \mathrm{g}{ }^{-1} \mathrm{~h}^{-1}$, batch 1 oxygen consumption rates between $0.18 \mu \mathrm{mol} \mathrm{g}^{-1} \mathrm{~h}^{-1}$ and $0.92 \mu \mathrm{mol} \mathrm{g} \mathrm{g}^{-1} \mathrm{~h}^{-1}$ (fig. 8a). There was a slight trend towards an increasing oxygen consumption of mussels at higher methane consumption rates $\left(\mathrm{MO}_{2}=1.06( \pm 3.15,95 \% \mathrm{CI}) \mathrm{MCH}_{4}+0.33( \pm\right.$ $0.28,95 \% \mathrm{CI})\left[\mu \mathrm{mol} \mathrm{g} \mathrm{g}^{-1} \mathrm{~h}^{-1}\right.$; regression: $\mathrm{R}^{2}=0.05, \mathrm{~F}=0.56, \mathrm{p}=0.47$; i. in fig. 8a). Methane consumption rates of batch $2 G$. childressi that were cultured with methane supply ('m' and ' $\mathrm{a}+\mathrm{m}$ ') ranged between $0.1 \mu \mathrm{mol} \mathrm{g} \mathrm{g}^{-1} \mathrm{~h}^{-1}$ and $0.23 \mu \mathrm{mol} \mathrm{g}^{-1} \mathrm{~h}^{-1}$ in 2017 and had increased to a range between $0.17 \mu \mathrm{mol} \mathrm{g}^{-1} \mathrm{~h}^{-1}$ and $0.82 \mu \mathrm{mol} \mathrm{g} \mathrm{g}^{-1} \mathrm{~h}^{-1}$ in 2019 (fig. 8b). In 2017, oxygen consumption of batch 2 mussels increased significantly with higher methane consumption rates: $\mathrm{MO}_{2}=2.19( \pm 1.78,95 \% \mathrm{CI}) \mathrm{MCH}_{4}+0.54( \pm 0.24,95 \% \mathrm{CI})\left[\mu \mathrm{mol} \mathrm{g}{ }^{-1} \mathrm{~h}^{-1}\right]$ (regression: $\mathrm{R}^{2}=0.55$, $\mathrm{F}=8.49, \mathrm{p}=0.023$; ii. in fig. $8 \mathrm{a})$.

\section{Activity and seawater methane concentrations}

The number of daily valve gape hours of batch 2 mussels averaged across all three repeated runs of diurnal variations of seawater $\mathrm{CH}_{4}$ concentration (fig. 5, suppl. fig. 5) was independent of the nutritional treatments the G. childressi were previously acclimated to (fig. 9). However, as a tendency, deep-sea mussels that were acclimatized to $\mathrm{CH}_{4}$ reacted slightly differently to changes in seawater $\mathrm{CH}_{4}$ than mussels that were exclusively acclimated to microalgae food without $\mathrm{CH}_{4}$ addition. Overall, we found a trend towards longest activity phases of G. childressi at intermediate seawater $\mathrm{CH}_{4}$ concentrations (20-45 $\left.\mu \mathrm{M}\right)$, and not at the highest concentration (57 $\mu \mathrm{M}$, fig. 10). All mussels reduced valve gaping time periods in the absence of $\mathrm{CH}_{4}$ in seawater. However, this pattern - as well as the reduced activity at the highest $\mathrm{CH}_{4}$ level - was most 
525

526

527

528

529

530

531

532

533

534

535

536

537

538

539

540

541

542

543

544

545

546

547

548

549

550

551

552

553

prominent at $G$. childressi that were acclimated to $\mathrm{CH}_{4}$ (' $\mathrm{m}$ ' and 'm+a', fig. 10a and 10b). The reactions of deep-sea mussels to changes in seawater $\mathrm{CH}_{4}$ appeared to be generally stronger when $\mathrm{CH}_{4}$ levels were gradually increased (suppl. fig. 6a-c) as to when the $\mathrm{CH}_{4}$ concentration was reduced (suppl. fig. 6d-f).

\section{Particulate food consumption}

Batch 1 G. childressi cleared both, Rhodomonas sp. and Nannochloropsis sp. cells from seawater (fig. 11a), however, Rhodomonas sp. at a higher rate. Larger mussels (shell length $85 \pm 7 \mathrm{~mm}$ ) were characterized by higher phytoplankton clearance rates than smaller mussels (shell length $51 \pm 3 \mathrm{~mm}$ ). After being cultured for eight months under different nutritional scenarios, batch 2 G. childressi were characterized by different Rhodomonas sp. clearance behaviors: mussels acclimated to $\mathrm{CH}_{4}$ and microalgae food supply ('a+m') cleared Rhodomonas at highest rates of $91.1 \mathrm{~mL} \mathrm{~h}^{-1}$ (fig. 11b) which corresponds to $6.4 \times 10^{5}$ cells $\mathrm{h}^{-1}$ (respectively $1.12 \mathrm{~J} \mathrm{~h}^{-1}$; at $1.75 \mu \mathrm{J} \mathrm{cell}^{-1}$; Riisgård et al. 2012). G. childressi that were previously acclimated to $\mathrm{CH}_{4}$-free seawater ('a') cleared Rhodomonas sp. in the absence of $\mathrm{CH}_{4}$ - but not when the seawater was enriched with $\mathrm{CH}_{4}$ (fig. 11b).

\section{Stable isotopes}

Tissue stable isotope values of the analyzed G. childressi $\left(\delta^{15} \mathrm{~N}:-2.57-1.22\right.$ and $\delta^{13} \mathrm{C}$ : -59.5- 54.4) were well in the range of those of other G. childressi specimen collected in the Green Canyon area in the Gulf of Mexico (MacAvoy et al. 2008; Becker et al. 2010). However, all cultured mussels had a slightly reduced $\delta^{13} \mathrm{C}$ fractionation as compared to mussels sampled when they arrived in Kiel (without being influenced by our artificial nutritional treatments: ' $\mathrm{t}_{0}$ ', fig. 12b). This effect was again slightly stronger in G. childressi that were cultured with microalgae only (without $\mathrm{CH}_{4}$ ) when compared with mussels cultured with $\mathrm{CH}_{4}$ supply. This agrees with the lower $\delta^{13} \mathrm{C}$ fractionation of Rhodomonas sp. microalgae as compared to the $\mathrm{CH}_{4}$ used to equilibrate the aquaria. Annual carbon turnover rates, calculated as $\% \Delta \delta^{13} \mathrm{C}_{\mathrm{ann}}$, were $7.9 \%$ for 'a'-cultured G. childressi and 7.6\% for 'm'-cultured mussels. Finally, only G. childressi that were acclimated to a microalgae diet ('a') showed a weak tendency towards a positive $\delta^{15} \mathrm{~N}$ 
554 fractionation (fig. 12a). The calculated annual $\mathrm{N}$ turnover rate $\left(\% \Delta \delta^{15} \mathrm{~N}_{\text {ann }}\right)$ of ' a' cultured

555 G. childressi was $3.9 \%$.

\section{Discussion}

558 Culture systems that allow for long-term studies of deep-sea organisms are difficult to realize and, hence, rare. Here, we present a recirculation aquarium system with an attached $\mathrm{CH}_{4}$-air gas mixing device, in which we can keep deep-sea mussels (G. childressi) for years in good condition. We also demonstrate that variation of seawater methane concentration impacts methane and oxygen consumption rates of experimental animals and show that acclimation of animals to different nutritional treatments influences whole-animal physiological properties.

564 These pilot experiments indicate a strong potential for our culture system to enable exciting experimental work to better understand nutritional bio-energetics of symbiont bearing deep-sea mussels.

567 Overall, we were able to design and set-up a safe recirculating culture system in this proof-of568 concept study to automatically supply deep-sea mussels with high methane levels for years. After overcoming technical limitations, namely sub-optimal production of the methane-air gas mixture

570 by the gas mixing device in the beginning of the culture period (batch 1 animals), stable

571 concentrations of 50-60 $\mu \mathrm{M}$ methane in seawater via equilibration with $4 \%$ methane in air gas

572 mixtures could be maintained consistently (fig. 5, suppl. fig. 1). It is not possibly to produce

573 higher methane concentrations using this system design, as the lower explosion limit for methane

574 does not allow for equilibration with gas mixtures containing more than $4.4 \%$ methane.

575 During the time in our culture system, G. childressi acquired energy, both, via their

576 methanotroph symbionts, which oxidize the methane provided into the culture system, and from

577 microalgae added to the seawater. Both nutritional strategies could be corroborated by direct

578 measurements of methane and microalgae uptake. The measured maximum methane

$579\left(<1 \mu \mathrm{mol} \mathrm{g} \mathrm{g}^{-1} \mathrm{~h}^{-1}\right)$ and oxygen $\left(<1.5 \mu \mathrm{mol} \mathrm{g} \mathrm{g}^{-1} \mathrm{~h}^{-1}\right)$ consumption rates of $G$. childressi cultured in

580 our system were lower than reported by Kochevar et al. (1992; III. in fig. 8a), who, however, had

581 a high variance in their data and measured at much higher seawater $\mathrm{CH}_{4}$ concentrations as well.

582 Metabolic rates appeared to be strongly reduced in batch 1 mussels, as can be seen when

583 comparing $\mathrm{O}_{2}$ consumption at similar $\mathrm{CH}_{4}$ consumption rates (offset of I. and III. in fig. 8a). 
Metabolic rates could be elevated by increasing $\mathrm{CH}_{4}$ supply about two-fold when culturing mussels of batch 2: $\mathrm{O}_{2}$ and $\mathrm{CH}_{4}$ consumption rates of mussels nourished with higher levels of $\mathrm{CH}_{4}$ for 4.5 months (II. in fig. 8a) were close to those measured by Kochevar et al. (1992). Furthermore, after another 2 years of culture, the batch $2 \mathrm{CH}_{4}$ consumption rates had increased substantially (fig. 8b), especially of those mussels that also received microalgae food ('a+m'). Lower methane consumption rates are likely due to a partial loss of methanotroph endosymbionts in the gills during transfer from the deep sea and culture under insufficient methane supply (Kádár et al. 2005). Batch 1 and 2 animals arrived in our lab 0.5 and 2 months post-capture, respectively, and we presume that methane supply in cultures post-capture and prearrival to Kiel (unquantified) was sub-optimal. Previous in situ work demonstrated that bathymodiolid mussels can rapidly lose most endosymbionts within weeks (Détrée et al. 2019). Thus, future culturing efforts should utilize experimental animals rapidly transferred from the site of capture to our culturing system to prevent this initial loss in symbiont density and diversity.

The observed up to 4-fold increase in methane uptake rate of batch 2 mussels may be explained by a subsequent re-acquisition of methanotrophs under our improved culture system conditions (Kádár et al. 2005; Riou et al. 2008; Tietjen et al., unpublished results). Deep-sea mussels that were fed only with microalgae apparently lost all methanotroph symbionts, as indicated by a lack of methane consumption after an acclimation time of 3.5 months to this regime (Fig. 8b). While microalgae-fed animals could maintain a relatively high condition, they were characterized by a much lower survival than methane acclimated groups, indicating the ultimately unsustainability nature of this nutritional treatment. These mussels' valve gape activity was relatively unaffected by methane concentration during our behavior monitoring trials (fig. 10). However, they filtered Rhodomonas sp. from the seawater only in the absence of methane, indicating a fundamental change in whole organism physiology and behavior elicited by our acclimation treatment. This was a surprising observation as the ventilation rate of G. childressi-unlike that of M. edulis - is assumed to be independent of stimuli by the filtered particles in suspension (Page et al 1990). Also, to our knowledge, no direct methane-sensing organ has been described for deep-sea mussels so far. However, valve gape activity of mussels cannot be directly translated into ventilation or filtration rate, as gill-cilia driven water convection rate can be controlled independently of valve gape (Riisgård et al. 2011). On average, G. childressi valve gape opening 
615

616

617

618

619

620

621

622

623

624

625

626

627

628

629

630

631

632

633

634

635

636

637

638

639

640

641

642

643

644

645

probability for $\mathrm{CH}_{4}$-supplied experimental groups increased when methane concentration was gradually increased with a maximum at intermediate values $(20-45 \mu \mathrm{M})$. We assume that this preference of intermediate methane concentrations can be attributed to an increase in metabolic activity of the methanotroph endosymbiont bacteria with rising methane concentrations and a saturation of their methane requirements at high seawater methane concentrations. How methane demand of endosymbionts and water convection rate by the mussel are coordinated and regulated, is unclear and can be explored in future experiments using our culturing system.

Besides a reasonably good condition index of $G$. childressi cultured in our recirculation aquarium system, almost no shell length growth and only low shell thickness growth could be detected. In comparison, shell length increments of several $\mathrm{mm}$ per year have been observed in the field at a seep nearby the sampling station our animals originated from (GC 234; Nix et al. 1995). The methane concentrations in our cultivation system - which are still lower than measured at many cold seep sites - are unlikely to be the main reason for the lower growth rates: Nix et al. (1995) measured similar or even lower methane concentrations at sites where much higher shell length growth rates of G. childressi were observed. Furthermore, G. childressi in our culture were in good body condition, able to invest surplus energy into shell thickness growth and, hence, not starving. However, our measured methane consumption rates suggest that the mussels lost a number of their methanotroph symbionts during transfer from the deep sea to our culture system - and that these were only partially able to re-grow. A higher number of 'farmed' symbionts would certainly allow experimental animals to invest more energy into shell (length) growth.

However, whole soft tissue stable isotope data clearly indicates that both nutritional strategies, (consumption of farmed endosymbionts, consumption of microalgae cells) were utilized by our cultured mussels. While the $\delta^{13} \mathrm{C}$ of $-59.3 \%$ of mussels sampled upon arrival at GEOMAR ('to') indicates a significant input of biogenic methane (typically $<-60 \%$ ) at the sampling site GC249, the lower $\mathrm{C}$ isotope fractionation of the cultured G. childressi mussels ( $\mathrm{m}_{\mathrm{c}}$ : ' $\mathrm{m}$ ', 'a+m' and 'a') can only be explained by uptake of thermogenic methane (from gas cylinders: $\delta^{13} \mathrm{C}=-42.5 \%$ ) and / or microalgae (Rhodomonas sp.: $\delta^{13} \mathrm{C}=-34 \%$; Brooks et al. 1987; Kennicutt et al. 1992; Becker et al. 2010). The obvious delta of mussel soft tissue $\delta^{13} \mathrm{C}$ and the $\delta^{13} \mathrm{C}$ of the $\mathrm{C}$ sources (thermogenic methane, respectively Rhodomonas sp.), $\Delta \delta^{13} \mathrm{C}$, though, can be interpreted as incomplete soft tissue turnover (Dattagupta et al. 2004). Annual C turnover $(<10 \%$ for ' $\mathrm{a}$ ' and 
646

647

648

649

650

651

652

653

654

655

656

657

658

659

660

661

662

663

664

665

666

667

668

669

670

671

672

673

674

675

' $m$ ' nutritional groups) are significantly lower than the 40\% - 78\% Dattagupta et al. (2004) calculated for G. childressi that were transplanted in the field and displayed strong shell growth and also than the $35 \%-53 \%$ the authors calculated for transplanted mussels that did not grow after transplantation. Thus, metabolism and growth of G. childressi living in our deep-sea recirculation aquarium system appears to have been reduced.

While post-capture loss and reduced density of symbionts during most of the culture time within our culture system may partially explain the low growth rates observed, low hydrostatic pressure might be another contributing factor. (Severe) depressurization damage to DNA and shell integrity has been described, however, predominantly for bathymodiolids collected from depths $>1000$ m (Dixon et al. 2004, Kadar et al. 2008). Dixon et al. (2004) suggest a physiological barrier for populations from depths $>1000-1500 \mathrm{~m}$ that prevents successful acclimation to surface pressures. For G. childressi that live in shallower habitats ( $<1000 \mathrm{~m})$, Arellano \& Young $(2009,2011)$ demonstrated that gamete release and development of viable larvae can be induced at surface pressure. These findings, in combination with our results, indicate that culturing efforts under surface pressure may be sufficient to study a range of important biological processes in G. childressi from relatively shallow deep-sea habitats. Studies utilizing shallow water invertebrates could demonstrate significant physiological plasticity during acclimation to pressures resembling water depths of ca. $1000 \mathrm{~m}$, with changes in membrane composition ('homeoviscous adaptation') likely contributing to survival at elevated pressures (Brown et al. 2019). Thus, plastic re-organization of cellular structures might enable some marine invertebrates to acclimate to pressures in the 1-100 bar range in both directions. However, comparative growth trials of experimental G. childressi at ambient vs. high pressure (50-80 bar) are needed to quantify the impacts of hydrostatic pressure variation on fitness. Thus, a further development of the described culture system to support long-term experiments under pressures of up to 80 bar would be needed. Further, meaningful ecological studies will need multiple culturing systems with separate filtering and methane sensing systems for replicated measurements and factorial experiments. Due to the relatively low costs of methane sensing equipment, this seems a realistic option for the near future (Bastviken et al. 2020). 
677 We have shown that our newly designed recirculating culture system is suitable for long-term maintenance experiments with cold seep colonizing G. childressi, at seawater methane

679 concentrations that can be found in natural deep-sea habitats of this species. Nutritional regimes involving controlled microalgae and continuous methane addition enabled good maintenance of body condition and some shell growth. Long-term acclimation of G. childressi to relatively high methane concentrations (ca. 50-60 $\mu \mathrm{M}$ ) can increase methane uptake rates of experimental animals, indicating that symbiont depleted animals may be able to increase symbiont density again. On the other hand, we show that acclimation to a microalgae diet without addition of methane leads to phenotypes that do not consume methane anymore, suggesting loss of symbionts.

Thus, with the caveats mentioned above in mind (potential depressurization pathologies), a number of exciting questions can be addressed with the described system if it is properly replicated. First, experimental modulation of symbiont density through seawater methane supply will enable fundamental studies related to nutritional contributions of particulate food vs. energy and nutrients derived from consumption of symbionts to the host mussel energy budget.

692 Metabolic exchange processes between symbiotic partners can be studied, as well as methane sensing processes of mussel host and symbiont and how they drive water convection activity of the host to supply methane to symbionts. Arellano \& Young (2009) demonstrated successful generation of $G$. childressi larvae in the laboratory, but were only able to rear larval stages to the first shell forming stage. Future studies can build on this work and try to maintain mussels in good condition for reproduction, and then spawn parental animals to raise larval stages ideally to settlement. Such data is urgently needed to better constrain biophysical models to estimate

699 connectivity of deep-sea mussel populations (Breusing et al. 2016). Key parameters, such as 700 duration of larval development, swimming speed and behavior, as well as chemotactic abilities 701 are unknown at present. Methane sensing abilities of larvae and adults could be studied in detail 702 using our culturing system by creating methane gradients in behavioral trials. Currently, nothing 703 is known about methane sensing abilities of G. childressi, but it is likely that unknown sense 704 organs exist to guide larvae to seep sites once they are competent for settlement and adults to 705 locations with optimum methane supply. Thus, we hope that culture systems as described here 
will stimulate more research to in detail investigate how these fascinating mussel holobionts function and how they can be protected in a deep-sea environment that is increasingly exploited.

\section{Acknowledgements}

We thank Nicole Dublier and Chuck Fisher for collection and transport to Germany of batch 1 mussels and Iliana Baums, Samuel Vohsen and, again, Chuck Fisher for collecting batch 2 mussels, giving them a temporary home at the Chuck Fisher deep-sea lab and sending them to GEOMAR and Ulrike Panknin for culturing Rhodomonas. This study was supported by the Cluster of Excellence ‘The Future Ocean' project 'Kiel Marine Organism Culture Centre KIMOCC', funded by the German Research Foundation (Deutsche Forschungsgemeinschaft) DFG.

\section{References}

Arellano, S.M. and C.M. Young. 2009. Spawning, Development, and the Duration of Larval Life in a Deep-Sea Cold-Seep Mussel. Biol. Bull. 216(2): 149-162. doi:10.1086/BBLv216n2p149

Arellano, S.M. and C.M. Young. 2011. Temperature and salinity tolerances of embryos and larvae of the deep-sea mytilid mussel "Bathymodiolus" childressi. Mar. Biol. 158(11): 24812493. doi:10.1007/s00227-011-1749-9

Bange, H.W., K. Bergmann, H.P. Hansen, A. Kock, R. Koppe, F. Malien and C. Ostrau. 2010. Dissolved methane during hypoxic events at the Boknis Eck time series station (Eckernförde Bay, SW Baltic Sea). Biogeosciences 7:1279-1284. doi:10.5194/bg-7-1279-2010

Bastviken, D., J. Nygren, J. Schenk, R. Parellada Massana and N.T. Duc. 2020. Technical note: Facilitating the use of low-cost methane $\left(\mathrm{CH}_{4}\right)$ sensors in flux chambers - calibration, data processing, and an open-source make-it-yourself logger, Biogeosciences 17:3659-3667. doi:10.5194/bg-17-3659-2020 
Becker, E.L., R.W. Lee, S.A. Macko, B.M. Faure and C.R. Fisher. 2010. Stable carbon and nitrogen isotope compositions of hydrocarbon-seep bivalves on the Gulf of Mexico lower continental slope. Deep-Sea Res. II 57:1957-1964. doi:10.1016/j.dsr2.2010.05.002

Berger, M.S. and C.M. Young. 2006. Physiological response of the cold-seep mussel Bathymodiolus childressi to acutely elevated temperature. Mar. Biol. 149(6): 1397-1402. doi:10.1007/s00227-006-0310-8

Bergquist, D.C., C. Fleckenstein, J. Knisel, B. Begley, I.R. MacDonald and C.R. Fisher. 2005. Variations in seep mussel bed communities along physical and chemical environmental gradients. Mar. Ecol. Prog. Ser. 293: 99-108. doi:10.3354/meps293099

Bettencourt, R., V. Costa, M. Laranjo, D. Rosa, L. Pires, A. Colaço,.H. Lopes and R. SerrãoSantos. 2011. Out of the deep sea into a land-based aquarium environment: investigating physiological adaptations in the hydrothermal vent mussel Bathymodiolus azoricus. ICES J. Mar. Sci. 68(2): 357-364. doi:10.1093/icesjms/fsq119

Billett, D.S.M., R.S. Lampitt, A.L. Rice and R.F.C. Mantoura. 1983. Seasonal sedimentation of phytoplankton to the deep-sea benthos. Nature. 302: 520-522. doi:10.1038/302520a0

Bleich, M., F. Melzner, C. Hiebenthal, H. Mempel, K. Schulz, U. Riebesell, M. Wahl, F. Sommer, U. Sommer, A. Form, U. Piatkowski, R. Hanel, D. Piepenburg, M. Spindler, A. Eisenhaue, A. Franke, V. Möller, G.A. Baumert and C. Clemmesen. 2008. Kiel CO 2 manipulation experimental facility $\left(\mathrm{KICO}_{2}\right)$. Second Symposium on the Ocean in a High- $\mathrm{CO}_{2}$ World, Monaco, 06 - 09.10.2008, doi:10.13140/2.1.3818.0809

Breusing, C., A. Biastoch, A. Drews, A. Metaxas, D. Jollivet, R. C. Vrijenhoek, T. Bayer, F. Melzner, L. Sayavedra, J.M. Petersen, N. Dubilier, M.B. Schilhabel, P. Rosenstiel, T.B.H. Reusch. 2016. Biophysical and Population Genetic Models Predict the Presence of "Phantom" Stepping Stones Connecting Mid-Atlantic Ridge Vent Ecosystems. Curr. Biol. 26(17):22572267. doi:10.1016/j.cub.2016.06.062

Brooks, J.M., M.C. Kennicutt II, C.R. Fisher, S.A. Macko, K. Cole, J.J. Childress R.R., Bidigare and R.D. Vetter. 1987. Deep-sea hydrocarbon seep communities: Evidence for energy and nutritional carbon sources. Science 238:1138-1142. doi:10.1126/science.238.4830.1138 
Brown, A., S. Thatje, A. Martinez, D. Pond, A. Oliphant. 2019. The effect of high hydrostatic pressure acclimation on acute temperature tolerance and phospholipid fatty acid composition in the shallow-water shrimp Palaemon varians. J. Exp. Mar. Biol. Ecol. 514-515: 103-109. doi:10.1016/j.jembe.2019.03.011

Cary, S.C., C.R. Fisher and H. Felbeck. 1988. Mussel growth supported by methane as sole carbon and energy source. Science. 240(4848): 78-80. doi:10.1126/science.240.4848.78

Childress, J.J., C.R. Fisher, J.M. Brooks, M.C. Kennicutt, II, R. Bidigareand and A.E. Anderson. 1986. A Methanotrophic Marine Molluscan (Bivalvia, Mytilidae) Symbiosis: Mussel fueled by Gas. Science. 233(4770): 1306-1308. doi:10.1126/science.233.4770.1306

Colaço, A., I. Martins, M. Laranjo, L. Pires, C. Leal, C. Prieto, V. Costa, H. Lopes, D. Rosa, P.R. Dando and R. Serrão-Santos. 2006. Annual spawning of the hydrothermal vent mussel, Bathymodiolus azoricus, under controlled aquarium conditions at atmospheric pressure. J. Exp. Mar. Biol. Ecol. 333: 166-171. doi:10.1016/j.jembe.2005.12.005

Cordes, E.E., D.C. Bergquist and C.R. Fisher. 2009. Macro-Ecology of Gulf of Mexico Cold Seeps. Ann. Rev. Mar. Sci. 1: 143-168. doi:10.1146/annurev.marine.010908.163912

Coughlan, J., 1969. The estimation of filtering rate from the clearance of suspensions. Mar. Biol. 2(4): 356-358. doi:10.1007/BF00355716

Dattagupta, S., D.C. Bergquist, E.B. Szalai, S.A. Macko and C.R. Fisher. 2004. Tissue carbon, nitrogen, and sulfur stable isotope turnover in transplanted Bathymodiolus childressi mussels: Relation to growth and physiological condition. Limnol. Oceanogr. 49(4):1144-1151. doi:10.4319/lo.2004.49.4.1144

Dattagupta, S., J. Martin, S.M. Liao, R.S. Carney and C.R. Fisher. 2007. Deep-sea hydrocarbon seep gastropod Bathynerita naticoidea responds to cues from the habitat-providing mussel Bathymodiolus childressi. Mar. Ecol. 28(1): 193-198. doi:10.1111/j.1439-0485.2006.00130.x

Davenport, J. and X. Chen. 1987. A comparison of methods for the assessment of condition in the mussel (Mytilus edulis L .). J. Molluscan Stud. 53: 293-297. doi:10.1093/mollus/53.3.293 
Détrée, C. I. Haddad, E. Demey-Thomas, J. Vinh, F.H. Lallier, A. Tanguy and J. Mary. 2019. Global host molecular perturbations upon in situ loss of bacterial endosymbionts in the deep-sea mussel Bathymodiolus azoricus assessed using proteomics and transcriptomics. BMC Genomics 20, 109. doi:10.1186/s12864-019-5456-0

Dixon, D.R., A.M. Pruski, L.R.J Dixon. 2004.The effects of hydrostatic pressure change on DNA integrity in the hydrothermal-vent mussel Bathymodiolus azoricus: implications for future deep-sea mutagenicity studies. Mutat. Res.-Fundam. Mol. Mech. Mutagen. 552(1-2): 235-246. doi:10.1016/j.mrfmmm.2004.06.026

Duperron, S., M. Sibuet, B.J. MacGregor, M.M.M. Kuypers, C.R. Fisher and N. Dubilier. 2007. Diversity, relative abundance and metabolic potential of bacterial endosymbionts in three Bathymodiolus mussel species from cold seeps in the Gulf of Mexico. Environ. Microbiol. 9(6): 1423-1438. doi:10.1111/j.1462-2920.2007.01259.x

Faure, B., S.W. Schaeffer and C.R. Fisher. 2015. Species Distribution and Population Connectivity of Deep-Sea Mussels at Hydrocarbon Seeps in the Gulf of Mexico. PLoS ONE 10(4): e0118460. doi:10.1371/journal.pone.0118460

Fiala-Médioni, A., C. Métivier, A. Herry and M. Le Pennec. 1986. Ultrastructure of the gill of hydrothermal-vent mytilid Bathymodiolus sp. Mar. Biol. 92:65-72. doi:10.1007/BF00392747

Fisher, C.R. and J.J. Childress. 1992. Organic carbon transfer from methanotrophic symbionts to the host hydrocarbon-seep mussel. Symbiosis, 12(3): 221-235.

Foster-Smith, R.L. 1975. The effect of concentration of suspension on the filtration rates and pseudofaecal production for Mytilus edulis L., Cerastoderma edule (L.) and Venerupis pullastra (Montagu). J. Exp. Mar. Biol. Ecol. 17(1): 1-22. doi: 10.1016/0022-0981(75)90075-1

Gage, J.D. 2003. Food Inputs, Utilization, Carbon Flow and Energetics. In: P. A. Tyler, ed. Ecosystems of the world, Vol. 28. Ecosystems of the deep oceans. Amsterdam: Elsevier Science, pp. 313-380.

Génio, L., S. Kiel, M.R. Cunha, J. Grahame and C.T.S. Little. 2012. Shell microstructures of mussels (Bivalvia: Mytilidae: Bathymodiolinae) from deep-sea chemosynthetic sites: Do they 
have a phylogenetic significance? Deep-Sea Res. Part I-Oceanogr. Res. Pap. 64:86-103. doi:10.1016/j.dsr.2012.02.002

Gustafson, R.G., R.D. Turner, R.A. Lutz and RC. Vrijenhoek. 1998. A new genus and five new species of mussels from deep sea sulfide/hydrocarbon seeps in Gulf of Mexico. Malacologia, 40(1-2): 63-112.

Holcomb, M., A.L. Cohen and D.C. McCorkle. 2013. An evaluation of staining techniques for marking daily growth in scleractinian corals. J. Exp. Mar. Biol. Ecol. 440:126-131. doi:10.1016/j.jembe.2012.12.003

Huang, H., Y. Shen, Z. Yang, H. Zhao, C. Sheng, Y. Guo and Y. Wei. 2019. A deep-sea largevolume high-pressure simulation system-design, analysis and experimental verification. Ocean Engineering. 180: 29-39. doi:10.1016/j.oceaneng.2019.03.050

Jacobs, P., K. Troost, R. Riegman and J. van der Mee. 2015. Length- and weight-dependent clearance rates of juvenile mussels (Mytilus edulis) on various planktonic prey items. Helgoland Mar. Res. 69(1): 101-112. doi:10.1007/s10152-014-0419-y

Kádár, E., R. Bettencourt, V. Costa, R.S. Santos, A. Lobo-da-Cunha and P. Dando. 2005. Experimentally induced endosymbiont loss and re-acquirement in the hydrothermal vent bivalve Bathymodiolus azoricus. J. Exp. Mar. Biol. Ecol. 318:99-110. doi:10.1016/j.jembe.2004.12.025

Kadar, E., A.G. Checa, A.N.D P. Oliveira and J.P. Machado. 2008. Shell nacre ultrastructure and depressurisation dissolution in the deep-sea hydrothermal vent mussel Bathymodiolus azoricus. J. Comp. Physiol. B. 178:123-130. doi:10.1007/s00360-007-0178-z

Kennicutt II, M.C., R.A. Burke Jr., I.R. MacDonald, J.M. Brooks, G.J. Denoux and S.A. Macko. 1992. Stable isotope partitioning in seep and vent organisms: chemical and ecological significance. Chem. Geol. 101:293-310. doi:10.1016/0009-2541(92)90009-T

Kochevar, R.E., J.J. Childress, C.R. Fisher and E. Minnich. 1992. The methane mussel: roles of symbiont and host in the metabolic utilization of methane. Mar. Biol. 112(3): 389-401. doi:10.1007/BF00356284

MacAvoy, S.E., R. S. Carney, E. Morgan, and S. A. Macko. 2008. Stable Isotope Variation Among the Mussel Bathymodiolus childressi and Associated Heterotrophic Fauna at Four ColdSeep Communities in the Gulf of Mexico. J. Shellfish Res. 27(1):147-151. doi:10.2983/07308000(2008)27[147:SIVATM]2.0.CO;2 
MacDonald, I.R., W.R. Callender, R.A. Burke Jr., S.J. McDonald and R.S. Carney. 1990. Finescale distribution of methanotrophic mussels at a Louisiana cold seep. Prog. Oceanogr. 24(1-4): 15-24. doi:10.1016/0079-6611(90)90016-U

Martins I., A. Colaço, P.R. Dando, I. Martins, D. Desbruyères, P.-M. Sarradin, J.C. Marques and R. Serrão-Santos. 2008. Size-dependent variations on the nutritional pathway of Bathymodiolus azoricus demonstrated by a C-flux model. Ecol. Model. 217:59-71. doi:10.1016/j.ecolmodel.2008.05.008

McCollom, T.M. and E.L. Shock. 1997. Geochemical constraints on chemolithoautotrophic metabolism by microorganisms in seafloor hydrothermal systems. Geochim. Cosmochim. Acta. 61(20): 4375-4391. doi:10.1016/S0016-7037(97)00241-X

Nagarajan, R., S.E.G. Lea, J.D. Goss-Custard. 2006. Seasonal variations in mussel, Mytilus edulis L. shell thickness and strength and their ecological implications. J. Exp. Mar. Biol. Ecol. 339(2): 241-250. doi:10.1016/j.jembe.2006.08.001

Nedoncelle, K., F. Lartaud, M. de Rafelis, S. Boulila and N. Le Bris. 2013. A new method for high-resolution bivalve growth rate studies in hydrothermal environments. Mar. Biol. 160:14271439. doi:10.1007/s00227-013-2195-7

Nishijima, M., D.J. Lindsay, J. Hata, A. Nakamura, H. Kasai, Y. Ise, C.R. Fisher, Y. Fujiwara, M. Kawato and T. Maruyama. 2010. Association of Thioautotrophic Bacteria with Deep-Sea Sponges. Mar. Biotechnol. 12: 253-260. doi:10.1007/s10126-009-9253-7

Nix, E.R., C.R. Fisher, J. Vodenichar and K.M. Scott. 1995. Physiological ecology of a mussel with methanotrophic endosymbionts at three hydrocarbon seep sites in the Gulf of Mexico. Mar. Biol. 122(4): 605-617. doi:10.1007/BF00350682

Page, H.M., C.R. Fisher and J.J. Childress. 1990. Role of filter-feeding in the nutritional biology of a deep-sea mussel with methanotrophic symbionts. Mar. Biol. 104(2): 251-257. doi:10.1007/BF01313266

Paull, C.K., B. Hecker, R. Commeau, R.P. Freeman-Lynde, C. Neumann, W.P. Corso, S. Golubic, J.E. Hook, E. Sikes and J. Curray. 1984. Biological Communities at the Florida Escarpment Resemble Hydrothermal Vent Taxa. Science. 226(4677): 965-967. doi:0.1126/science.226.4677.965 
872 Ramesh, K., M.Y. Hu, J. Thomsen, M. Bleich and F. Melzner. 2017. Mussel larvae modify

873 calcifying fluid carbonate chemistry to promote calcification. Nat. Commun. 8, 1709.

874 doi:10.1038/s41467-017-01806-8

875 Ravaux, J., N. Léger, G. Hamel and B. Shillito. 2019. Assessing a species thermal tolerance

876 through a multiparameter approach: the case study of the deep-sea hydrothermal vent shrimp

877 Rimicaris exoculate. Cell Stress and Chaperones. 24: 647-659. doi:10.1007/s12192-019-01003-0

878 Renaud, S.M., L.-V. Thinh and D.L. Parry. 1999. The gross chemical composition and fatty acid 879 composition of 18 species of tropical Australian microalgae for possible use in mariculture. 880 Aquaculture 170(2): 147-159. doi:10.1016/S0044-8486(98)00399-8

881 Riisgård, H.U., P.P. Egede and I. Barreiro Saavedra. 2011. Feeding Behaviour of the Mussel, 882 Mytilus edulis: New Observations, with a Minireview of Current Knowledge. Journal of Marine 883 Sciences, Vol. 2011, Article ID 312459, 13pp. doi:10.1155/2011/312459

884 Riisgård, H.U., D. Pleissner, K. Lundgren and P.S. Larsen. 2012. Growth of mussels Mytilus 885 edulis at algal (Rhodomonas salina) concentrations below and above saturation levels for 886 reduced filtration rate. Mar. Biol. Res. 9(10):1005-1017. doi:10.1080/17451000.2012.742549

887 Riou, V., S. Halary, S. Duperron, S. Bouillon, M. Elskens, R. Bettencourt, R. S. Santos, F. 888 Dehairs and A. Colaço. 2008. Influence of $\mathrm{CH}_{4}$ and $\mathrm{H}_{2} \mathrm{~S}$ availability on symbiont distribution, 889 carbon assimilation and transfer in the dual symbiotic vent mussel Bathymodiolus azoricus.

890 Biogeosciences 5: 1681-1691. doi: 10.5194/bg-5-1681-2008

891 Riou., V., A. Colaço, S. Bouillon, A.s Khripounoff, P. Dando, P. Mangion, E. Chevalier, M.

892 Korntheuer, R. Serrão Santos and F. Dehairs. 2010. Mixotrophy in the deep sea: a dual

893 endosymbiotic hydrothermal mytilid assimilates dissolved and particulate organic matter. Mar.

894 Ecol. Prog. Ser. 405:187-201. doi:10.3354/meps08515

895 Sanders, H.L. and R.R. Hessler. 1969. Ecology of the Deep-Sea Benthos. Science. 163(3874):

896 1419-1424. doi:10.1126/science.163.3874.1419

897 Seed, R.. 1968. Factors Influencing Shell Shape in the Mussel Mytilus Edulis. J. Mar. Biol.

898 Assoc. U.K., 48(3), 561-584. doi:10.1017/S002531540001915 
Sharp J.H. 1974. Improved analysis for "particulate" organic carbon and nitrogen from seawater. Limnol. Oceanogr. 19(6): 984-989. doi:10.4319/lo.1974.19.6.0984

Sibuet, M. and K. Olu. 1998. Biogeography, biodiversity and fluid dependence of deep-sea coldseep communities at active and passive margins. Deep Sea Research Part II: Topical Studies in Oceanography. 45(1-3): 517-567. doi:10.1016/S0967-0645(97)00074-X

Smith, K., 1985. Deep-sea hydrothermal vent mussels: nutritional state and distribution at the Galapagos Rift. Ecology. 66(3): 1067-1080.

Smith, E.B., K.M. Scott, E.R. Nix, C. Korte, C.R. Fisher. 2000. Growth and condition of seep mussels (Bathymodiolus childressi) at a Gulf of Mexico brine pool. Ecology, 81(9): 2392-2403. doi: 10.1890/0012-9658(2000)081[2392:GACOSM]2.0.CO;2

Streams, M.E., C.R. Fisher and A. Fiala-Médioni. 1997. Methanotrophic symbiont location and fate of carbon incorporated from methane in a hydrocarbon seep mussel. Mar. Biol. 129(3): 465476. doi:10.1007/s002270050187

Tunnicliffe, V., S.K. Juniper and M Sibuet. 2003. Reducing Enviroments of The Deep-Sea Floor. In: P. A. Tyler, ed. Ecosystems of the world, Vol. 28. Ecosystems of the deep oceans. Amsterdam: Elsevier Science pp. 81-110.

Vajedsamiei, J., F. Melzner, M. Raatz, R. Kiko, M. Khosravi and C. Pansch. 2021. Simultaneous recording of fltration and respiration in marine organisms in response to short-term environmental variability. Limnol. Oceanogr. Meth. 19(3):196-209. doi:10.1002/lom3.10414

Walne, P.R. 1970. Studies on the food value of nineteen genera of algae to juvenile bivalves of the genera Ostrea, Crassostrea, Mercenaria, and Mytilis. Fish. Invest., Lond., Ser. 2. 26: pp. 159. 162.

Wentrup, C., A. Wendeberg, M. Schimak, C. Borowski and N. Dubilier. 2014. Forever competent: Deep-sea bivalves are colonized by their chemosynthetic symbionts throughout their lifetime. Environ. Microbiol. 16:3699-3713. doi:10.1007/BF00392747 
924 Wiesenburg, D.A. and N.L. Guinasso. 1979. Equilibrium Solubilities of Methane, Carbon

925 Monoxide, and Hydrogen in Water and Sea Water. J. Chem. Eng. Data 24(4):356-360.

926 doi:10.1021/je60083a006

Tables:

Table 1. Overview of G. childressi experiments with mussels from batches 1 and 2. Numbers in brackets indicate the time ( $\mathrm{t}$, number of months) of culture after which the respective experiment was conducted. $t=0$ refers to time of arrival at GEOMAR, which corresponds to ca. 0.5 and 2 months post-capture for batches 1 and 2 , respectively.

\begin{tabular}{|c|c|c|c|}
\hline & & $\begin{array}{c}\text { Experiment } 1 \\
\quad(\text { batch 1) }\end{array}$ & $\begin{array}{c}\text { Experiment } 2 \\
\text { (batch 2) }\end{array}$ \\
\hline \multicolumn{2}{|c|}{ total culture duration: } & 36 months & 27 months \\
\hline \multirow{3}{*}{\multicolumn{2}{|c|}{$\begin{array}{l}\text { nutritional conditions during acclimation } \\
\text { phase: }\end{array}$}} & $20-30 \mu \mathrm{M} \mathrm{CH}_{4}$ & 'm': $60-70 \mu \mathrm{M} \mathrm{CH} 4$ \\
\hline & & & $\begin{array}{l}\text { ‘a+m': } 60-70 \mu \mathrm{M} \mathrm{CH}{ }_{4} \\
\quad+\text { Rhodomonas }\end{array}$ \\
\hline & & & 'a': Rhodomonas \\
\hline \multicolumn{4}{|c|}{ experiments / analyses conducted } \\
\hline \multicolumn{2}{|c|}{ Condition index $\left(\mathrm{C}_{\mathrm{i}}\right)$ : } & (23) & $(0,27)$ \\
\hline \multicolumn{2}{|l|}{ shell growth } & (23) & $(27)$ \\
\hline \multicolumn{2}{|c|}{$\mathrm{CH}_{4}$ and $\mathrm{O}_{2}$ consumption: } & $(17)$ & (3.5) \\
\hline \multicolumn{2}{|c|}{ (only) $\mathrm{CH}_{4}$ consumption: } & & (23) \\
\hline \multicolumn{2}{|c|}{ activity vs. $\left[\mathrm{CH}_{4}\right]$ : } & & $(15)$ \\
\hline \multirow{2}{*}{$\begin{array}{l}\text { microalgae } \\
\text { consumption }\end{array}$} & - Rhodomonas sp.: & $(25)$ & (8) \\
\hline & - Nannochloropsis sp.: & $(25)$ & \\
\hline \multicolumn{2}{|c|}{ stable isotopes } & & $(27)$ \\
\hline
\end{tabular}




\section{Figures:}

940

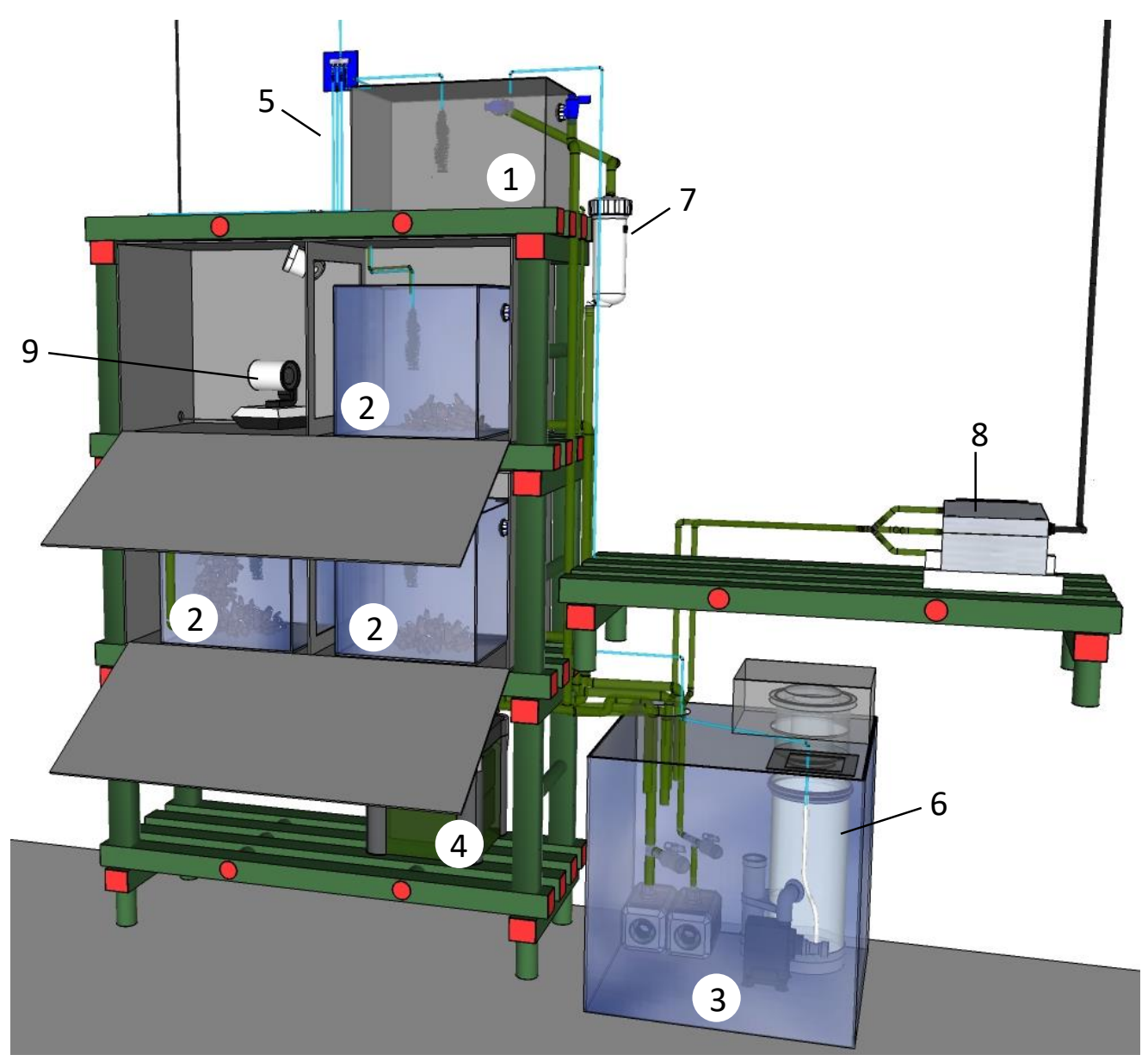

942 Figure 1. 3D sketch of the $200 \mathrm{~L}$ water recirculating culture system to maintain deep-sea

943 mussels G. childressi. Details: 1: header tank, 2: culture aquariums with deep-sea mussels, 3:

944 filter sump, 4: biofilter, 5: gas supply line with air-methane mixture, 6: protein skimmer, 7: UV-

945 sterilizer, 8: methane sensor, 9: IR-camera. 


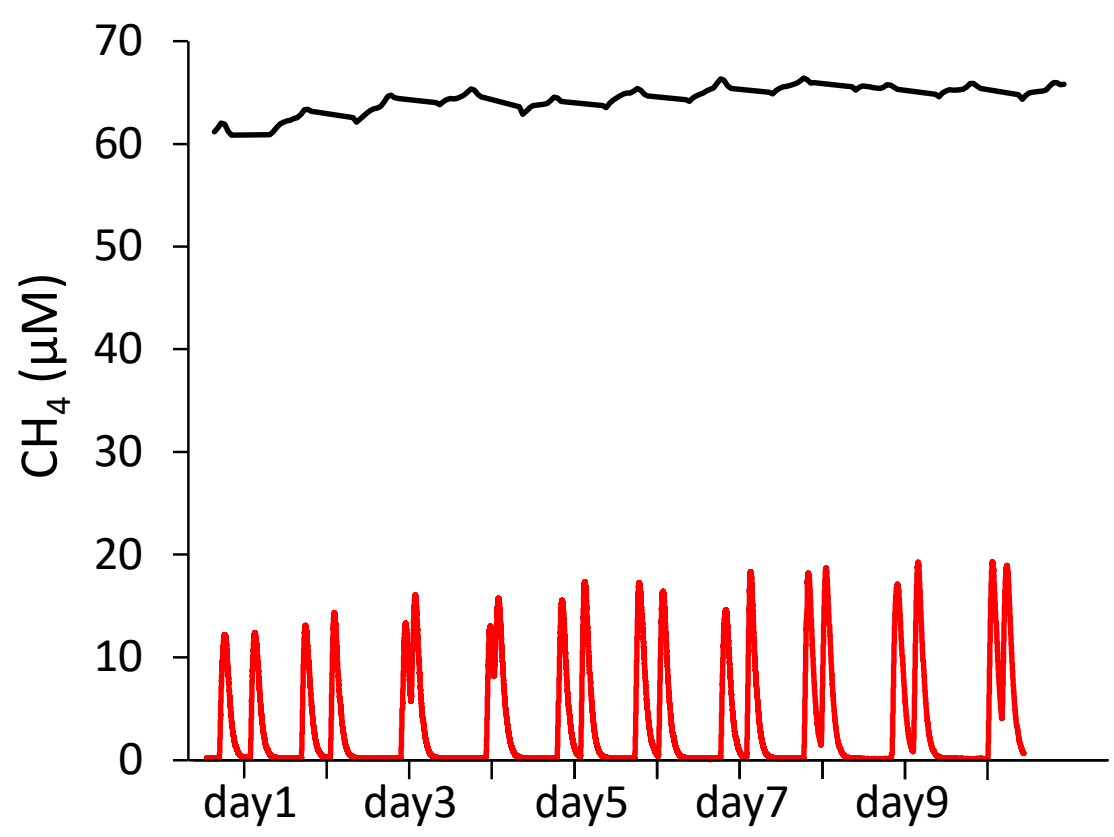

Figure 2. Comparison of intermittent methane feeding by repetitive addition of $5 \mathrm{~L}$ of methanesaturated seawater (after 15 minutes of equilibration with a gas diffusor stone, solution containing $\sim 8 \mathrm{mmol}_{\text {of }} \mathrm{CH}_{4}$ ) to the $200 \mathrm{~L}$ recirculation culture system (red line) with continuous methane feeding by bubbling with methane-enriched air (4\% methane) from the gas mixing device (black line) as measured with a CONTROS HydroC ${ }^{\circledR} \mathrm{CH}_{4}$ sensor in the filter tank. 


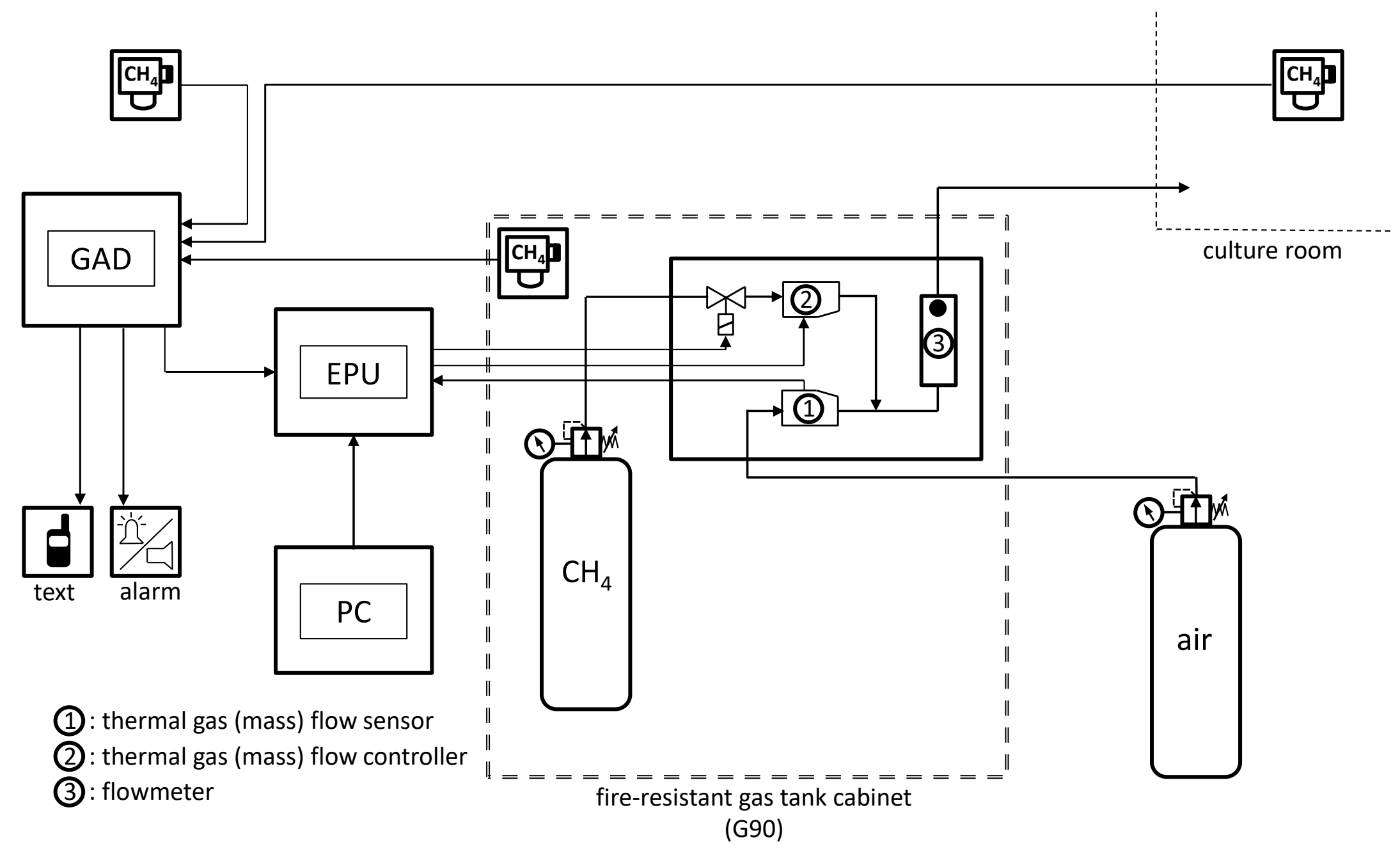

Figure 3. Technical sketch of the gas mixing device. The air flow is measured by the flow sensor (1) and an evaluating processor unit (EPU) controls how much methane is injected by the flow controller (2). Methane-air mixture flow can be controlled by a flowmeter

975 (3). A gas alarm device (GAD) receives methane level signals from 3 sensors (in the fire-resistant gas tank cabinet, in the gas mixture room and in the deep-sea mussel culture room) and triggers alarm signaling, text messaging and closing of the magnetic valve

977 (cutting-off methane flow) when alarm levels are reached. 


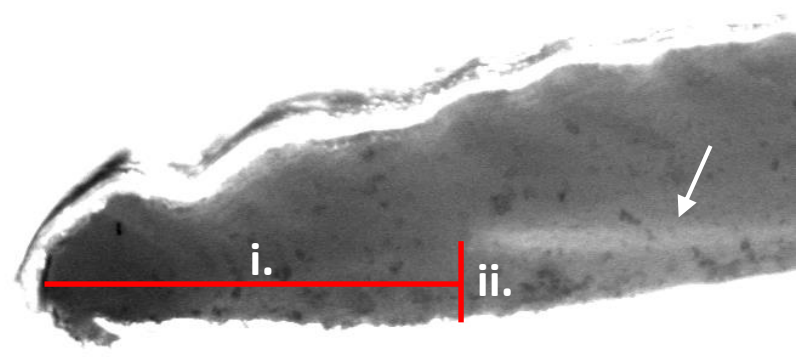

Figure 4. Shell length (i.) and thickness (ii.) growth measurements of cultured G. childressi from batch 1 after 23 months of culture. Calcein-marked growth bands (arrow) imaged with a Leica M165 FC fluorescence stereo microscope. Scale (black bars): $100 \mu \mathrm{m}$.

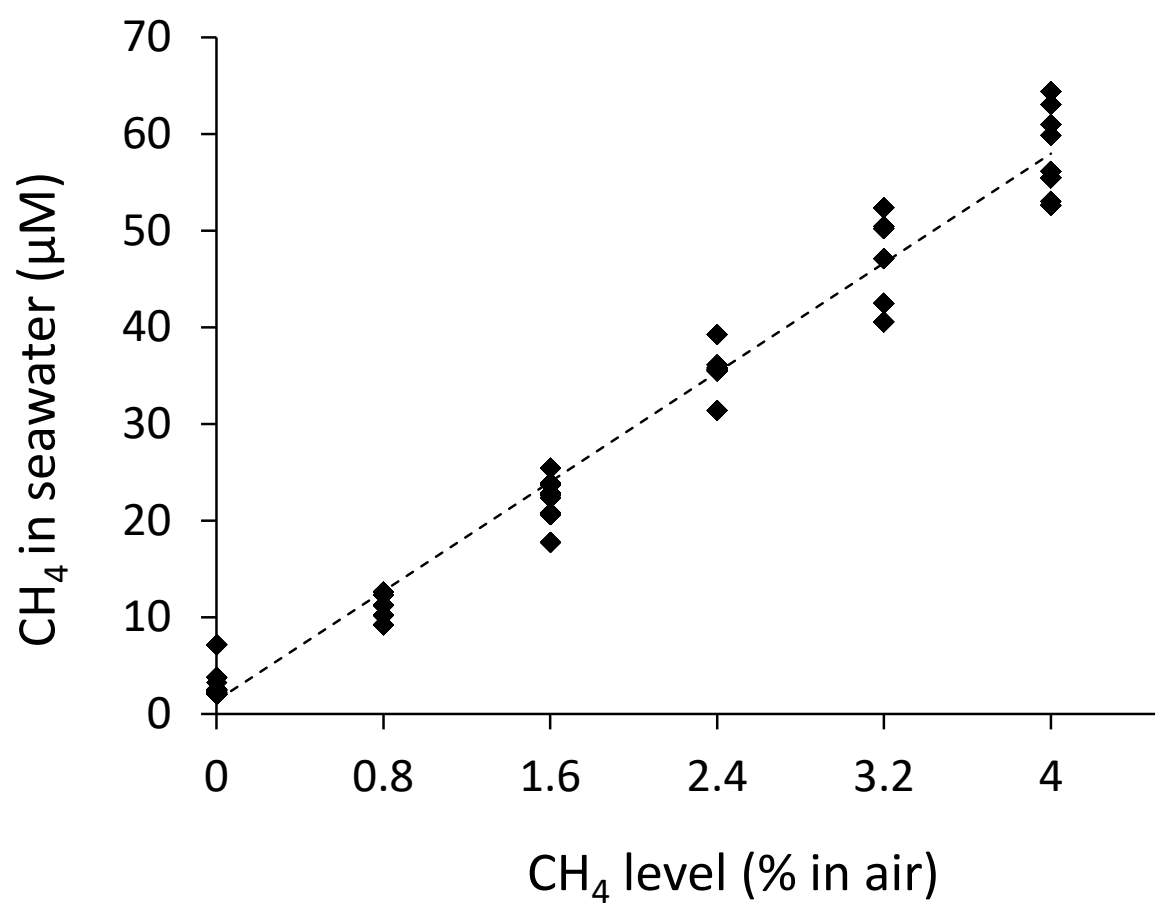

987 Figure 5. System performance during the mussel valve gape activity experiment: Daily averages 988 of measured $\mathrm{CH}_{4}$ concentrations in the recirculating aquarium system at six different $\mathrm{CH}_{4}$ concentrations $(\%)$ in the air used to equilibrate the seawater. $\mathrm{CH}_{4}(\mu \mathrm{M})=14.149 \% \mathrm{CH}_{4}+$ 1.3907; $\mathrm{R}^{2}=0.98$, regression: $\mathrm{F}=1294.2, \mathrm{p}<0.001 ; \mathrm{n}=6$. 


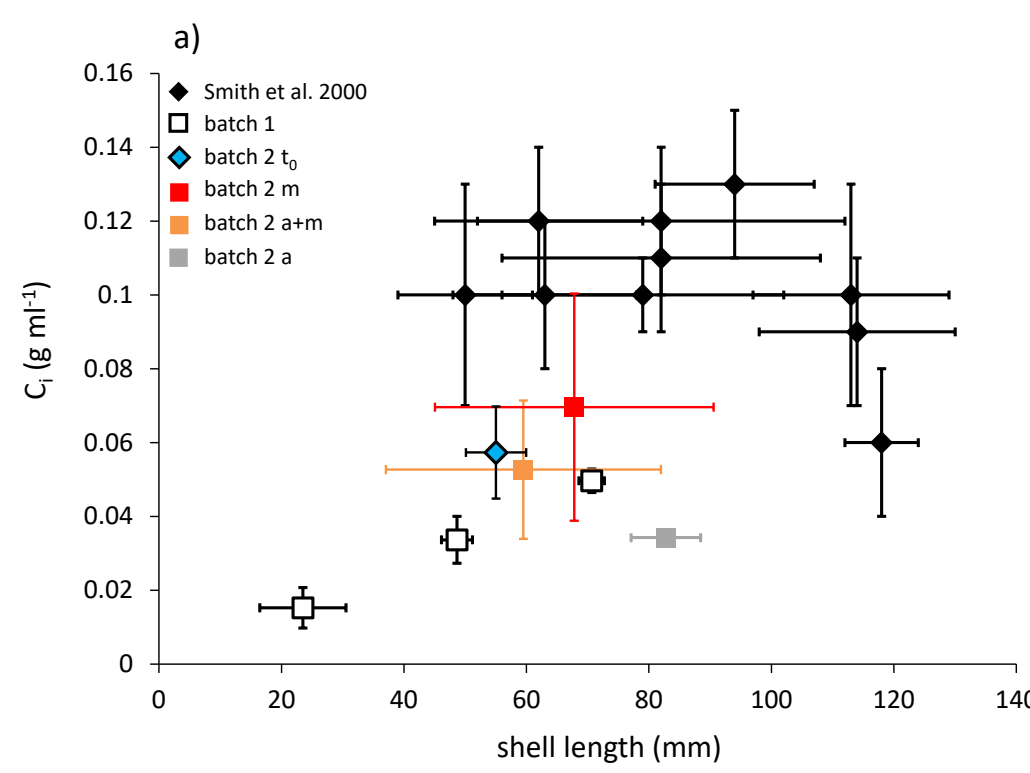

b)

c)
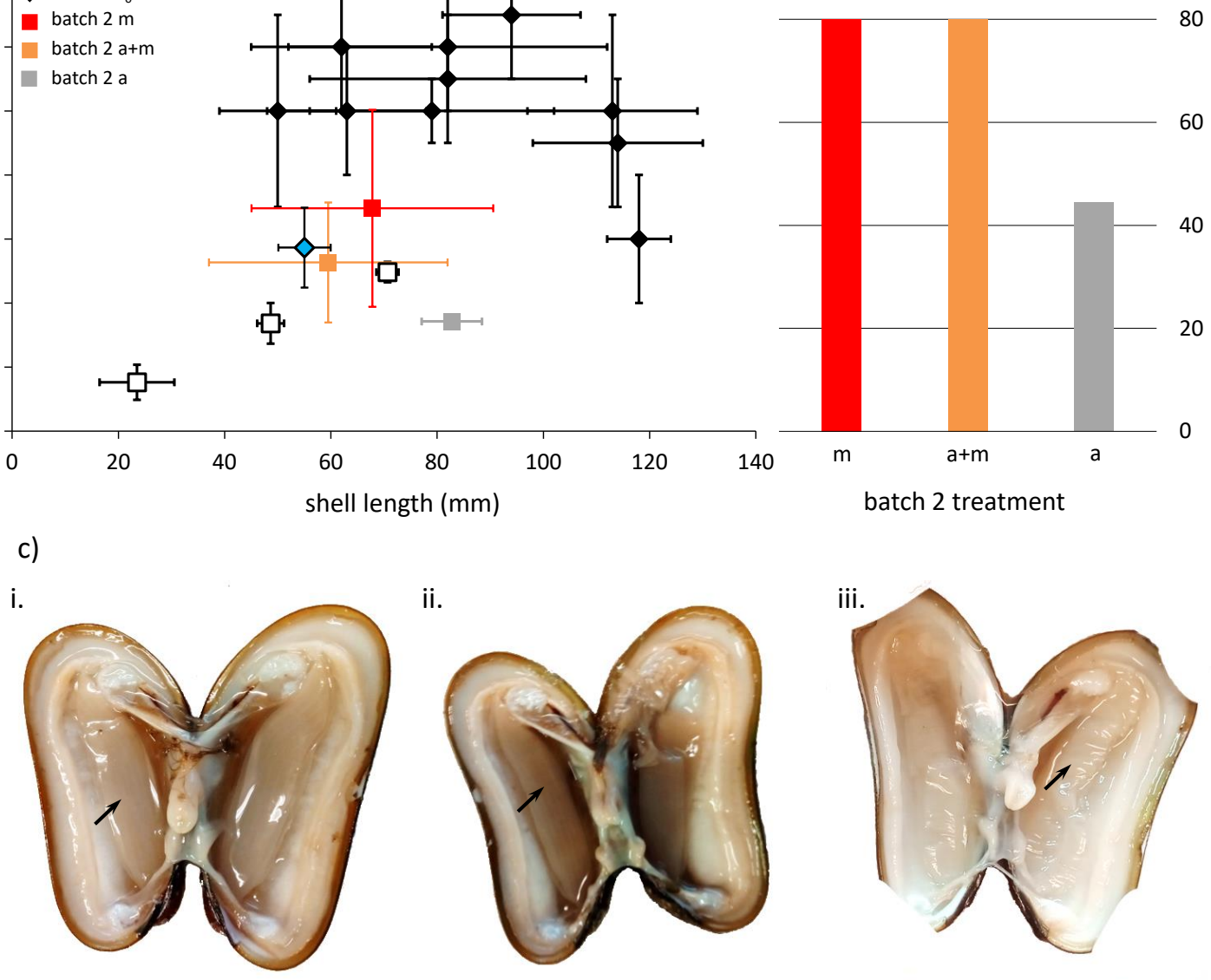

$\frac{\overline{0}}{\sum_{\overline{0}}^{\frac{0}{5}}}$

Figure 6. Condition (a, c) and survival (b) of batch 1 and 2 G. childressi. (a) Condition of ' $\mathrm{t}_{0}$ ' mussels was determined when batch 2 mussels arrived in Kiel. G. childressi from batch 1 (cultured from July 2014 to August 2016) as well as from three different nutritional treatments of batch 2 (cultured from August 2017 to November 2019, 'm': $\mathrm{CH}_{4}$, 'a+m': algae and $\mathrm{CH}_{4}$, 'a': algae) were sampled after 25 and 27 months of culture, respectively. Data in a) are mean \pm SD. (b) Mortality of animals in treatments ' $\mathrm{m}$ ', ' $\mathrm{a}+\mathrm{m}$ ' and ' $\mathrm{a}$ ', that were not sacrificed for other analyses (initial animal numbers: 9-10). (c) Examples of freshly sacrificed batch 2 mussels from different nutritional treatments $\left(\mathrm{CH}_{4}\right.$ : ' $\mathrm{m}$ ', algae $+\mathrm{CH}_{4}$ : 'a+m', only algae: 'a') illustrate white almost transparent - gills (arrows) of mussels fed without methane. 


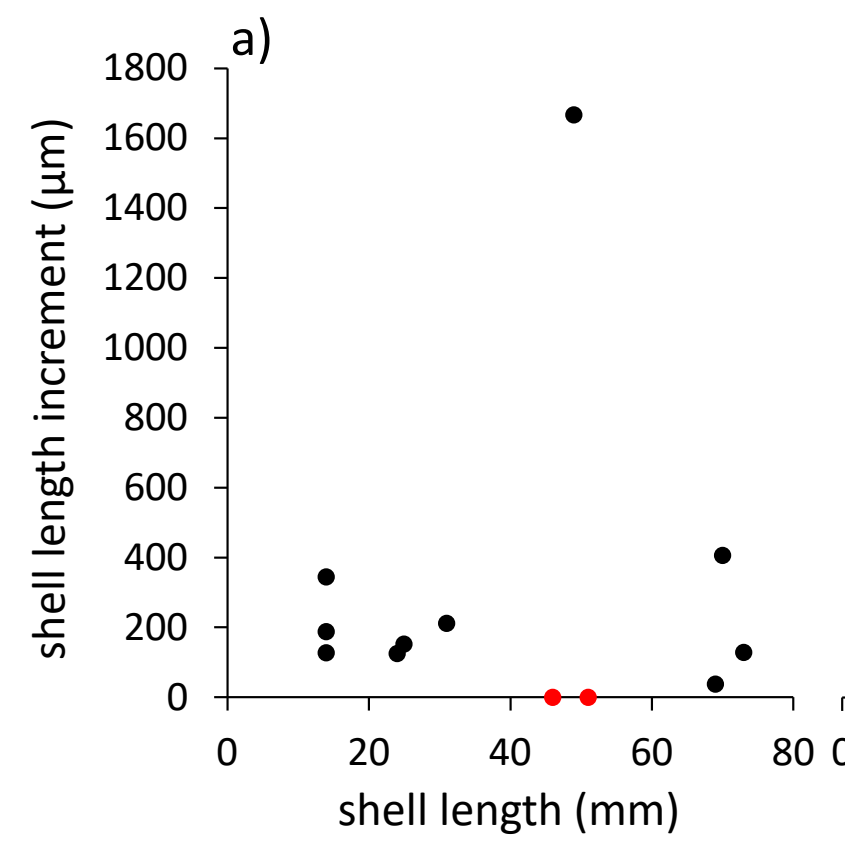

b)

1014 Figure 7. Batch 1 G. childressi shell length (SL, a) and shell thickness (ST, b) growth after 21 months, as deduced from calcein staining marks using a using a Leica M165 FC stereo microscope. Shell thickness increased exponentially increased with mussel size (b; ST increase $\left.(\mu \mathrm{m})=17.737 \mathrm{e}^{0.055 \mathrm{x}}, \mathrm{x}=\mathrm{SL}(\mathrm{mm}), \mathrm{R}^{2}=0.89\right)$. 
a)

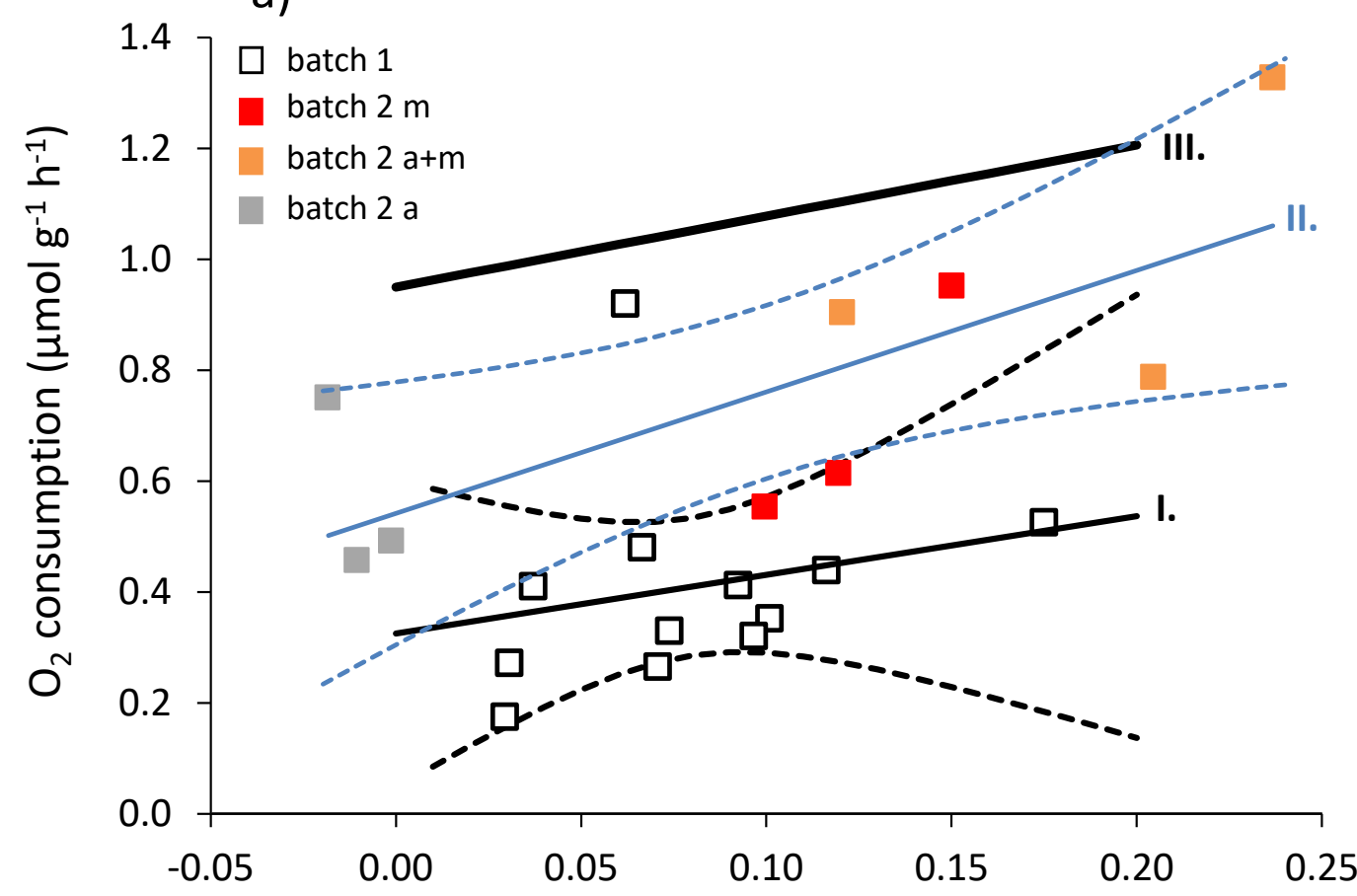

b)

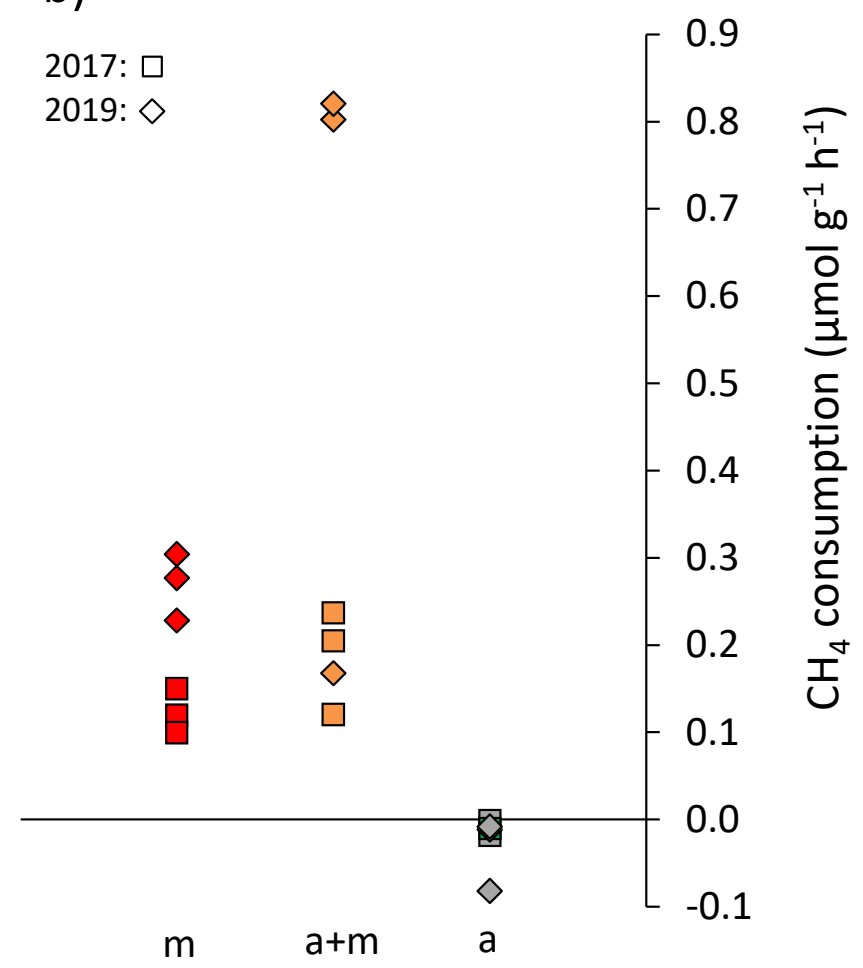

batch 2 treatment

Figure 8. Gas consumption of batch 1 and 2 G. childressi. Oxygen consumption depending on methane consumption rate (a) with similar average slope but overall lower oxygen uptake of cultured batch 1 animals (I.) as compared to the relationship found by Kochevar et al. (1992, III.: $\left.\mathrm{MO}_{2}\left(\mu \mathrm{mol} \mathrm{g} \mathrm{g}^{-1} \mathrm{~h}^{-1}\right)=1.19( \pm 0.09,95 \% \mathrm{CI}) \mathrm{MCH}_{4}\left(\mu \mathrm{mol} \mathrm{g}^{-1} \mathrm{~h}^{-1}\right)+0.95\right)$. Batch 2 mussels were cultured under 3 different nutrition regimes $\left(\mathrm{CH}_{4}\right.$ : ' $\mathrm{m}$ ', algae $+\mathrm{CH}_{4}$ : 'a+m', only algae: 'a'; II.). Dashed lines in a) represent $95 \%$ confidence envelopes. Methane consumption of batch 2 mussels was measured twice, in 2017 and 2019 (b). 


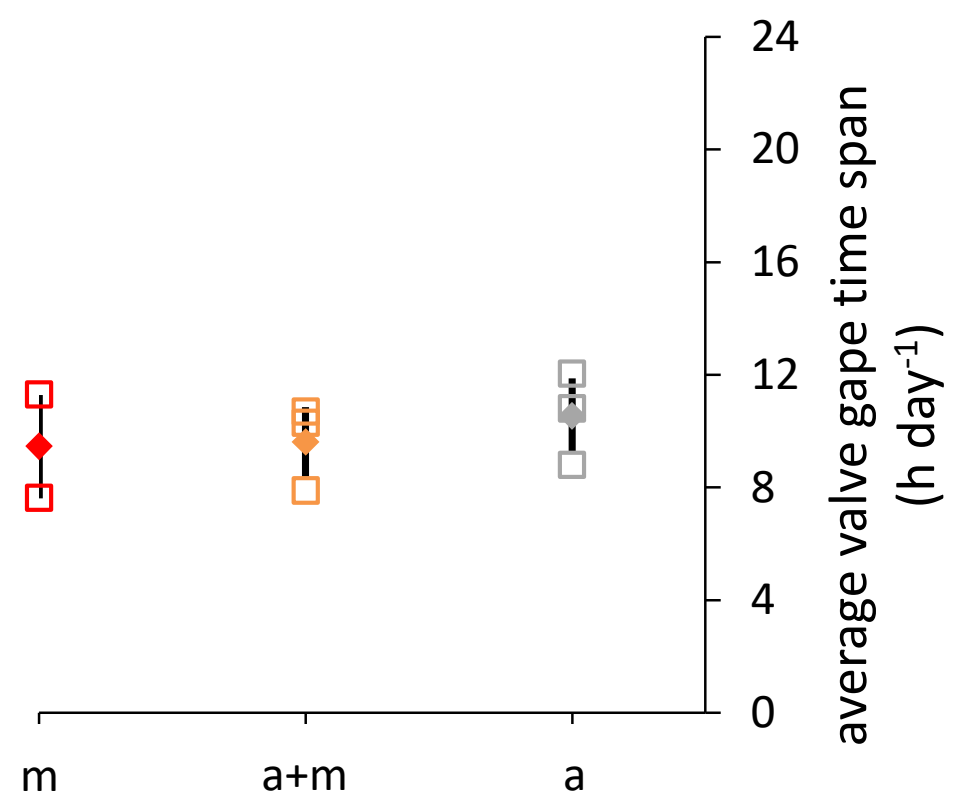

\section{batch 2 treatment}

1041 Figure 9. Average daily valve gape time of batch 2 G. childressi during the activity experiment

1042 based on time lapse image analysis. Mussels were cultured under 3 different nutritional regimes:

$1043 \mathrm{CH}_{4}$ : ' $\mathrm{m}$ ', algae $+\mathrm{CH}_{4}$ : 'a+m', only algae: 'a'. Diamonds: mean $\pm \mathrm{SD}$.

1044

1045

1046

1047

1048

1049

1050

1051

1052

1053

1054

1055

1056

1057

1058 


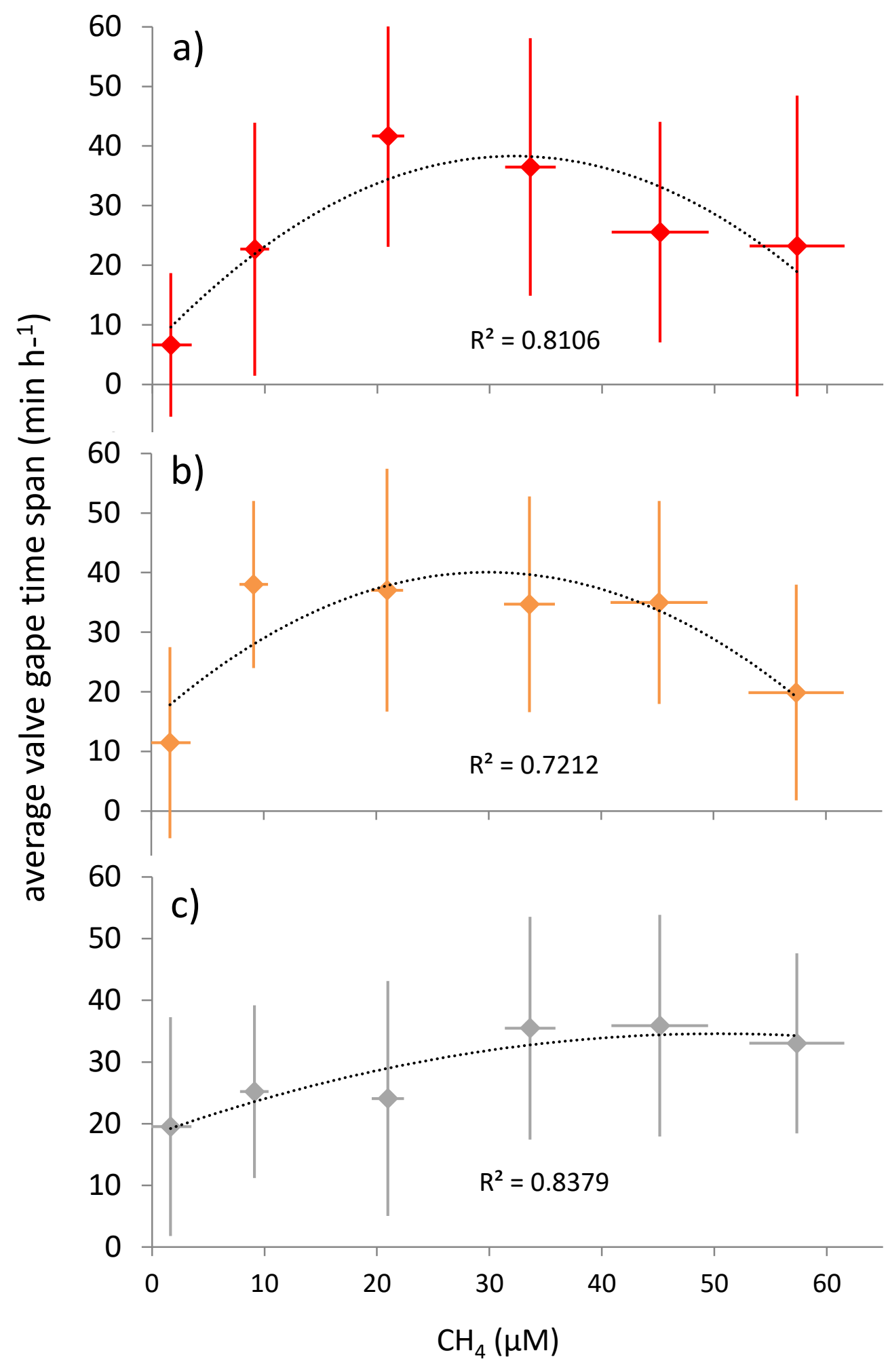

Figure 10. Valve gape activity of G. childressi mussels from different nutritional treatments (a: $\mathrm{CH}_{4}$ 'm', b: algae $+\mathrm{CH}_{4}$ 'a+m', c: algae 'a') in response to step-wise increasing and decreasing seawater $\mathrm{CH}_{4}$ concentrations (each 3 times) based on time lapse image analysis. Data are mean \pm $1063 \mathrm{SD}, \mathrm{n}=3$. 

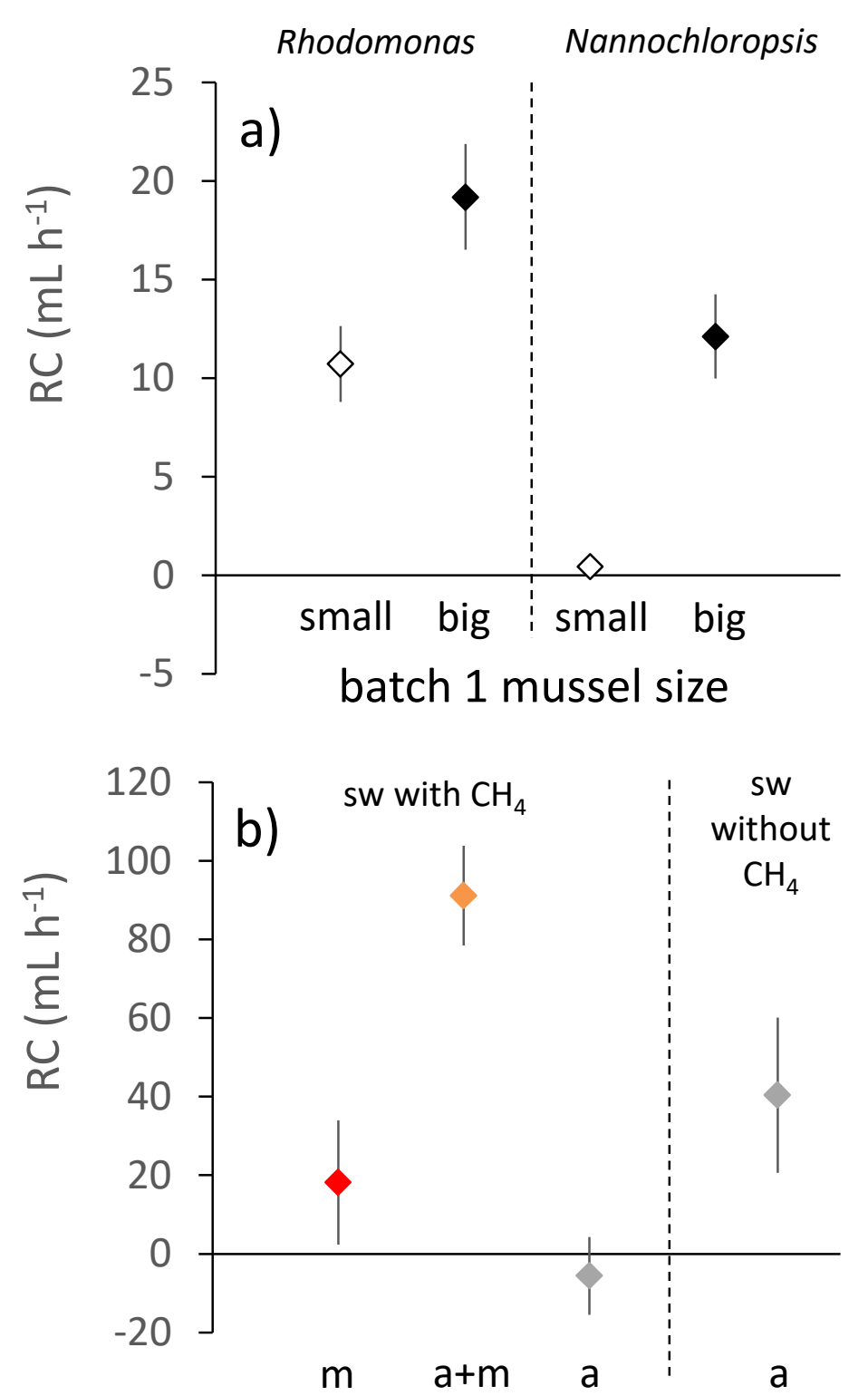

batch 2 nutrition

Figure 11. Clearance rates (RC) of G. childressi mussels filtering phytoplankton. (a) RC of different-sized batch 1 mussels ('small': $51 \pm 3 \mathrm{~mm} \mathrm{SD}$, 'large': $85 \pm 7 \mathrm{~mm} \mathrm{SD}$ ) that received either Rhodomonas or Nannochloropsis cells. (b) Clearance trials of batch 2 mussels from different nutritional treatments $\left(\mathrm{CH}_{4}\right.$ : ' $\mathrm{m}$ ', algae $+\mathrm{CH}_{4}$ : ' $\mathrm{a}+\mathrm{m}$ ', only algae: 'a') filtering Rhodomonas cells. The measurement of clearance rates of G. childressi cultured in the 'a' treatment (without $\mathrm{CH}_{4}$ supply) was conducted twice: once while mussels were placed in $\mathrm{CH}_{4}$ enriched seawater, and, subsequently, once without $\mathrm{CH}_{4}$. Data are mean $\pm \mathrm{SE}$. 

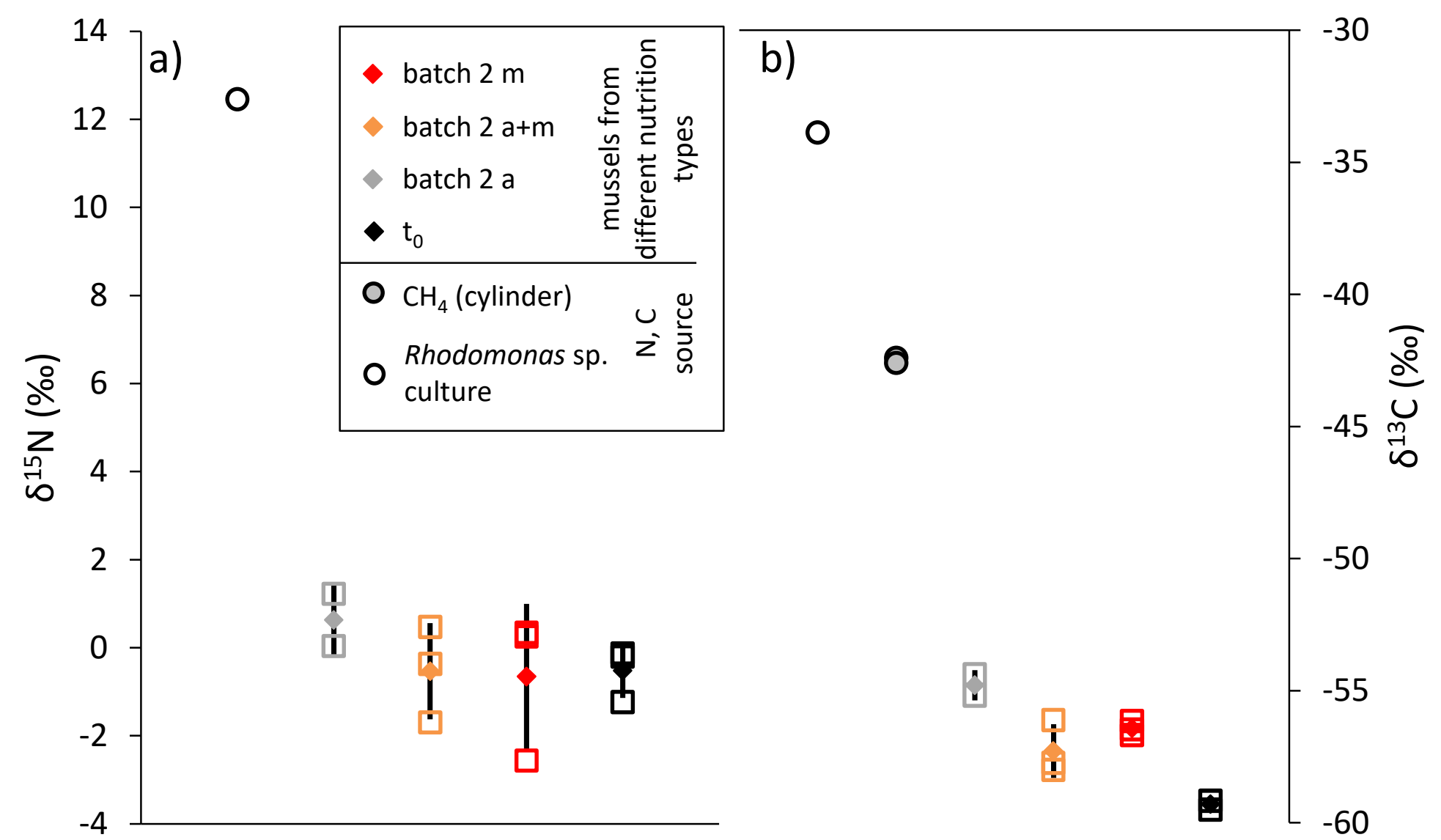

Figure 12. Stable isotopes (a: $\left.\delta^{15} \mathrm{~N}, \mathrm{~b}: \delta^{13} \mathrm{C}\right)$ of batch 2 G. childressi that experienced different nutritional regimes $\left(\mathrm{CH}_{4}:\right.$ ' $\mathrm{m}$ ', algae + $1077 \mathrm{CH}_{4}$ : 'a+m', only algae: 'a') in our culture. As reference, to animals were sampled upon arrival at GEOMAR after spending 2 months 1078 post-capture at Charles Fisher's 'deep-sea lab’ aquarium system, Pennsylvania State University. Diamonds: mean \pm SD. 